\title{
Health responses to a wealth shock: evidence from a Swedish tax reform
}

\author{
Oscar Erixson $^{1,2}$
}

Received: 8 April 2016 / Accepted: 11 May 2017 / Published online: 20 June 2017

(C) The Author(s) 2017. This article is an open access publication

\begin{abstract}
This paper makes two contributions to the literature on the effects of wealth on health. First, it deals with reverse causality and omitted variable bias by exploiting exogenous variation in inherited wealth generated by the repeal of the Swedish inheritance tax. Second, it analyzes responses in health outcomes through the use of administrative registers. The results show that increased wealth has limited short to medium run impacts on objective adult health. This is in line with what has previously been reported in the literature.
\end{abstract}

Keywords Inheritance $\cdot$ Tax reform $\cdot$ Wealth shock $\cdot$ Objective health

JEL Classification $\mathrm{D} 10 \cdot \mathrm{I} 10 \cdot \mathrm{I} 12 \cdot \mathrm{I} 14 \cdot \mathrm{H} 30$

\section{Introduction}

It has long been recognized that there is a positive relationship between many measures of economic wealth and a variety of health outcomes. ${ }^{1}$

This "gradient" is a significant concern for politicians and public health officials, as it implies that inequalities between rich and poor do not only appear as differences in consumption and material well-being, but also in life expectancy and quality of life. Unfortunately, any policy intervention targeted at reducing these inequalities, or

\footnotetext{
${ }^{1}$ See Marmot (1999), Smith (1999), Deaton (2003), and Cutler et al. (2011) for reviews of the literature.

Responsible editor: Erdal Tekin

Oscar Erixson

oscar.erixson@nek.uu.se

1 Uppsala Center for Fiscal Studies (UCFS), Department of Economics, Uppsala University, Box 513, SE-751 20 Uppsala, Sweden

2 Research Institute of Industrial Economics (IFN), Stockholm, Sweden
} 
promoting public health in general, suffers from the fact that we still know little about if and how wealth affects health.

Answering these questions is further complicated by the possibility that causality may go in the opposite direction, from health to wealth. ${ }^{2}$ It could also be that unobserved factors, such as genetics, early childhood exposures, or time preferences, influence wealth and health in the same direction without a causal link. ${ }^{3}$

Given the practical constraints involved in randomizing people to receive different amounts of wealth, researchers have tried to solve these methodological challenges with quasi-experimental designs, in particular by exploiting exogenous variation generated by individual wealth or income shocks. Important examples include lottery winnings (Lindahl 2005; Gardner and Oswald 2007; Apouey and Clark 2015; Cesarini et al. 2016), stock market fluctuations (Schwandt 2014), inheritances (Meer et al. 2003; Kim and Ruhm 2012; Carman 2013), and unanticipated policy changes (Jensen and Richter 2004; Case 2004; Frijters et al. 2005; Snyder and Evans 2006). ${ }^{4}$ The general finding is that wealth and income have a limited impact on adult health in the short to medium run.

Previous studies, however, are limited by the fact that they are almost entirely based on survey data on subjective general health status. Although it has been argued that subjective health status is a good predictor of future morbidity and mortality (Idler and Benyamini 1997; van Doorslaer and Gertham 2003), there are reasons for questioning its use as a dependent variable in this context. For instance, subjective health status is likely to be influenced by factors such as social norms regarding health and use of health care as well as how participants understand the survey questions, which in themselves are systematically related to wealth and income in such a way that the coefficient estimates are biased towards zero (see, for example, Murray and Chen 1992; Bago d'Uva et al. 2008). Moreover, subjective general health status does not separate between different aspects of health. For instance, it has been shown that, on the one hand, improved wealth leads to harmful behaviors such as smoking and drinking and, on the other hand, to reduced obesity, lower stress, and enhanced mental well-being, suggesting that important health effects may go undetected (Lindahl 2005; Apouey and Clark 2015; Kim and Ruhm 2012).

This paper manages causality by exploiting a previously untapped and policyrelevant source of exogenous variation in wealth, namely the repeal of the Swedish inheritance tax on December 17, 2004. ${ }^{5}$ Heirs who received inheritance above the tax threshold from parents who passed away after the reform are defined as being treated, as they experienced a favorable shock to their inheritances equal to what their tax payments would have been had the decedent died before the reform. Calculations indicate that this inheritance shock on average amounted to SEK 70,000 (about USD

\footnotetext{
${ }^{2}$ For examples of studies studying the impact of health shocks on labor market outcomes, see Lundborg et al. (2015), and on wealth, see $\mathrm{Wu}$ (2003).

${ }^{3}$ For studies discussing these issues, see for example Barker (1997), Almond and Currie (2013), Straus and Thomas (2008), Fuchs (1982), and Barsky et al. (1997).

${ }^{4}$ Other quasi-experimental designs in this context include IV estimators (see, for example, Ettner 1996) and Granger causality testing (see, for example, Adams et al. 2003 and Michaud and van Soest 2008).

${ }^{5}$ Eliason and Ohlsson (2013) use the repeal of the inheritance tax to study behavioral responses to taxation among individuals leaving inheritances to their heirs.
} 
9500 in 2004 value). This corresponds to around $7 \%$ of initial wealth or one quarter of annual taxable income.

The empirical strategy is to estimate the causal effect of the inheritance shock on health by approximating the counterfactual outcome with the health experiences of heirs who received inheritance above the tax threshold before the reform date, who subsequently received smaller inheritances than the treated heirs as they had to pay the inheritance tax. Thus, the treatment effect should be interpreted as the effect on health resulting from receiving an additional inheritance. ${ }^{6}$ While the inheritance shock is transitory and relatively limited in magnitude, which implies that its effects do not necessarily capture the relationship between permanent wealth and health, it does provide knowledge about the wealth effects generated by policy changes of similar magnitudes as the repeal of the Swedish inheritance tax affecting middle-aged individuals. In fact, I also report results showing that the impact of the inheritance shock is similar to the impact of inheritance as such. This broadens the generalizability of the main results further as inheritances represent one of the most common increases in wealth that people experience in life.

The relevant study population is collected from an administrative database covering the entire population of heirs of deceased Swedes over the time period of 2003-2005. Results from several tests show that the treated and the controls are comparable in predetermined characteristics, including health, implying that any difference in health between the two groups following the inheritance could reasonably be attributed to the inheritance shock. I also conduct placebo experiments, testing for responses among heirs for whom the reform should have no impact, and these results support the validity of the empirical strategy. Further support for this is given by an analysis showing that my main estimates are akin to the estimates obtained for a subsample of heirs whose parents passed away suddenly.

The health outcomes are collected from medical records, death certificates, and the Swedish sickness insurance register, and they all share the feature of being based on the medically qualified opinions of physicians. As far as I am aware, this is the first paper investigating the effects of increased economic resources on health by exploiting reforminduced variation in wealth and administrative individual-level data on health outcomes.

The main health outcome is an indicator of whether the individual has been hospitalized for any reason in a given year. Comparing the incidences of hospitalization between the treated and the controls over time - 10 years before and 6 years after the inheritance - shows that the inheritance shock increases the likelihood of hospitalization by around $5 \%$. This is equal to the impact of being 4 years older.

At a first glance, the positive effect on hospitalization may be interpreted as the inheritance shock having a detrimental consequence for health, especially since health care in Sweden is universal and basically free of charge. ${ }^{7}$ Tests for heterogeneous responses across diagnoses reported in connection with the hospital admissions, however, show that the wealth effect is only evident in two diagnosis categories: "symptoms and signs of disease" (e.g., shortness of breath, fever, general feeling of

\footnotetext{
${ }^{6}$ This is obviously a different margin than the relationship between inheritance and health, which could be obtained from a comparison between inheritors and non-inheritors. Such a comparison, however, would be problematic, as receiving an inheritance is commonly associated with grief and mourning, which in turn may have detrimental consequences for health.

${ }^{7}$ See Glenngård et al. (2005) for an excellent description of the Swedish health care system.
} 
illness) and "cancer." Regarding cancer, previous studies document that improved wealth leads to more smoking and drinking, behaviors that are positively related to the disease. However, it seems unlikely that the current wealth effect is operating through these channels, given the relatively limited time period over which it is estimated. If the inheritance shock leads to more smoking and drinking, we would instead see responses in diagnoses that are more immediately related to these risk factors (e.g., injuries, mental problems, respiratory diseases). Likewise, if the shock leads to reduced obesity or improved mental well-being (which has also been indicated by previous studies), we would be more likely to find a reduction in the incidence of cancer rather than an increase. One possible explanation is instead that cancer has been detected during health care visits for minor health problems (i.e., symptoms and signs of disease). That the inheritance shock leads to more health care visits, although health care is free in Sweden, could potentially be explained by people demanding good health in order to benefit fully from their improved prospects for future consumption.

To get a better understanding of how the inheritance shock affects different aspects of health, tests for responses in (publicly insured) sick leave amounting to more than 2 weeks in addition to in all-cause mortality are conducted, as these two health outcomes are likely to capture health events that are both more and less severe than those resulting in hospital admissions. The results show that the inheritance shock does not have any detectable effect on either of the two outcomes. Although the insignificant wealth effect on sick leave may be attributed to the fact that the analysis is based on the working-age population (for whom the inheritance shock has no detectable effect on hospitalization), the finding lends additional support to the conclusion that the inheritance shock has a negligible consequence on health. The insignificant effect on mortality is expected given the insignificant effect on the prevalence of diseases other than cancer (for which the impact is apparently too small to translate into mortality, at least over a period of 6 years).

In sum, the results show that increased wealth has limited short to medium run consequences for objective adult health. This is line with the findings in previous studies.

The outline of this paper is as follows. In Section 2, I discuss the theoretical predictions regarding the effect of wealth on health, together with an overview of the previous empirical literature. Section 3 describes the inheritance tax, with a particular focus on its unexpected repeal. In Section 4, I discuss the data used in the empirical analysis. Section 5 presents the empirical strategies and in Section 6, I present evidence suggesting that the inheritance shock is exogenous. Section 7 contains the results, Section 9 presents a discussion on the generalizability of the findings, and finally, Section 8 provides a concluding discussion.

\section{Review of related literature}

This section starts with a discussion on the theoretical arguments for why increased wealth may affect health. The second subsection is a review of the previous empirical literature regarding adult health. ${ }^{8}$ The general finding is that wealth shocks have a

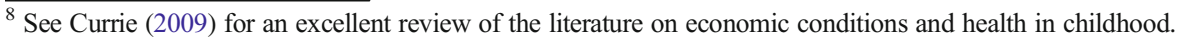


limited impact on longevity and self-assessed general health status. On the one hand, however, it appears as if improved financial resources lead people to engage in more behaviors and lifestyles that are possibly detrimental to their health in the long run (e.g., smoking and drinking), whereas, on the other hand, improved financial resources also have beneficial consequences in the form of reduced obesity, lower stress, and improved mental well-being.

\subsection{Theoretical arguments for causal effects of wealth on health}

The common hypothesis found in the literature is that improved economic resources lead to better health. Although this is largely motivated by stylized facts regarding the positive correlation between wealth and health, theoretical support for this hypothesis may be found in Grossman's model of health capital (Grossman 1972, 2000). ${ }^{9}$ According to this model, people demand health for the associated consumption benefits (good health gives utility), in addition to the associated production benefits (more healthy time available for work, consumption, and health investments). Healthy time available for market and non-market activities depends on the stock of health capital, which depreciates throughout the lifecycle until it reaches a threshold after which death take place. The individual, however, may counteract the deterioration process by investing in her health. In accordance with Becker's household production model (Becker 1976), health is produced by combining market goods and time. More wealth will make health investments subjectively cheaper and lead to increased demand for health and, eventually, improved health.

In recent years, there have been additions made to the health-capital model in order to account for the possibility that the individual not only derives utility from healthenhancing consumption (e.g., healthy foods and exercise), but also from consumption that is negatively correlated with health (e.g., drinking and smoking), see for example Galama and van Kippersluis (2010) and van Kippersluis and Galama (2014). ${ }^{10}$ According to these models, improved economic resources will relax the individual's budget constraint, thus allowing for a higher level of both types of consumption. Nevertheless, as unhealthy consumption is associated with a cost in the form of reduced health and a shorter lifespan, the rise in healthy consumption will be relatively larger.

\subsection{Findings in the previous literature}

Three previous studies have used inheritances to identify the effects of wealth on health outcomes. Meer et al. (2003) use data from the Panel Study of Income Dynamics (PSID) to analyze the impact of wealth on self-reported health status. The authors use receiving an inheritance as an instrument for changes in wealth, and they find what they interpret as "a quantitatively small effect" and conclude that the link between wealth and health is not driven by short-term changes in wealth. There are two concerns regarding the identification strategy employed by Meer et al. First, inheritances may not

\footnotetext{
${ }^{9}$ See Muurinen (1982) and Ehrlich and Chuma (1990) for extensions of the Grossman framework.

${ }^{10}$ These extensions are largely motivated by epidemiological research, which documents that a large fraction of the socioeconomic disparities in adult health in developed countries can be accounted for by disparities in lifestyles and consumption (McGinnis and Foege 1993; Mokdad et al. 2004; Contoyannis and Jones 2004; Cutler et al. 2011).
} 
be randomly distributed, but rather correlated with unobserved determinants of health. Second, the interpretation of the wealth effect is complicated by the fact that people may anticipate that they will receive an inheritance. If the heir has adjusted her health behavior or lifestyle in anticipation of an inheritance, then the estimate will understate the true effect. In a related study, Kim and Ruhm (2012) compare health consequences of people in the Health and Retirement Study (HRS) who have received inheritances in excess of USD 10,000 with people who have inherited small amounts ( $<$ USD 10,000), which are assumed not to affect health. The authors attempt to account for unobserved individual heterogeneity by estimating models with large sets of observable characteristics, including lagged health, and they exploit data on the individual's subjective probability of receiving an inheritance in order to address the issue of possible anticipatory effects. The results show that the wealth shock has no effect on selfreported health status, whereas it seems to lead to an increase in the prevalence and intensity of social drinking, in addition to a reduction in obesity. In a recent study, Carman (2013) makes a contribution to the two previous studies by comparing the results from models with and without individual fixed effects to test for the influence of unobserved heterogeneity across individuals in the PSID who have both received and not received inheritances. The first main result of the paper is that the inherited amount does not have any effect on self-reported health status, independent of model specification. The second main result is that the effect of receiving an inheritance (irrespectively of amount) is positive and significant in the specification without fixed effects, but not in the fixed effects specification. This suggests that individuals who receive an inheritance have better health than those who do not receive any inheritance, but that there is no improvement in health following the receipt.

Another source of plausibly exogenous variation in economic resources is lottery winnings. Using data on lottery winners from the Swedish Level of Living Surveys, Lindahl (2005) finds that increased income is associated with improved health, measured by an index of self-reported illnesses and symptoms, as well as increased life expectancy. The income effect on health appears to be the strongest for the oldest individuals. Moreover, Lindahl (2005) finds evidence of decreased obesity as a result of higher lottery winnings, suggesting that wealth may affect health through health-related consumption, such as exercise and healthy food. Unfortunately, however, the sample is limited to winners and contains no information on the frequency of playing the lottery. In a related study, Gardner and Oswald (2007) focus solely on lottery winners in the British Household Panel Survey and identify causation that varies according to the size of the prize. By doing so, they implicitly assume that winners of small and large prizes have similar unobserved characteristics, which is not obvious. Their results show that winning a large prize, compared to a small prize, enhances subjective mental wellbeing 2 years after winning. Apouey and Clark (2015) use the same dataset and identification strategy as Gardner and Oswald to test for responses, not only in mental well-being but also in self-reported measures concerning physical and general health. Their results show that the wealth shock has no detectable effect on general health, but that it does lead to improved mental health. The authors explain the lack of effect on the former variable by showing that winning the lottery leads to more smoking and drinking, behaviors with plausibly detrimental effects on general health. The main objection against lottery winnings is that they are randomly assigned and only conditional upon participation in the lottery, meaning that the results may be confounded by 
selection bias (van Kippersluis and Galama 2014). More specifically, because lottery players tend to have lower income and less education than non-players, the empirical estimates are likely to be generalizable only to the lower segments of the socioeconomic distribution. Cesarini et al. (2016) make a contribution to the previous studies by using a sample of around three million Swedish lottery players, covering individuals throughout the socioeconomic distribution. Another novel feature of this data is it contains information on the individual's expenditures associated with the lottery, thus enabling the authors to effectively control for the probability of winning the prize. The results show that the prize money has no detectable impact on health care utilization and mortality over a period of 10 years, which subsequently casts some doubt on the identification strategies in previous lottery studies. However, the study does find that the wealth shock decreases the consumption of drugs related to mental health. This could potentially be interpreted as if increased wealth has an anxiolytic influence on stress.

Stock market fluctuations constitute another source of variation in wealth that is unlikely to be induced by health (Smith 1999). Schwandt (2014) exploits the wealth gains and losses generated in the US stock market during a time period of 18 years. Using data on a sample of retirees from the HRS, he finds that a $10 \%$ wealth increase over 2 years leads to a significant improvement in an index constructed of different survey measures of physical and mental health, as well as reduced mortality. It appears as if the wealth shock reduces the incidence of heart-related diseases, hypertension, and psychiatric problems, suggesting that psychological factors may be the mechanism through which the wealth effect operates. As with lottery winnings, however, stock market swings are experienced by a specific subset of the population, which in this case tends to be relatively wealthy (Mankiw and Zeldes 1991; Poterba and Samwick 2003; Smith 2004).

A second branch of studies in the field has exploited variation in income and wealth generated by changes in government policies. One advantage with policy changes is that they usually affect a larger segment of the population. From a policy perspective, they may therefore be more relevant than individual shocks. Using cross-sectional data on self-reported health status of Black South Africans who saw their income double due to a change in the pension system, Case (2004) finds evidence of improvements in general health. Interestingly, these not only manifest themselves for the recipient, but for all household members. ${ }^{11}$ Moreover, Case shows that the effect is likely to stem from improved sanitation, housing, and health care as well as reduced stress. However, it is unclear whether these results are applicable to a Western population. ${ }^{12}$ Jensen and Richter (2004) study a pension crisis in Russia during which many retirees did not receive their pensions for an extended period of time. Examining the longitudinal effects of this adverse shock, the authors find evidence of reduced nutritional intake and utilization of health care in the short run. They also find that the likelihood of dying within 2 years of the crisis

\footnotetext{
${ }^{11}$ Dufflo (2000) similarly documents that the pension reform had positive health consequences for young children (especially girls) in the household.

${ }^{12}$ See Straus and Thomas (2008) for an excellent review of the literature on economics and health in developing countries.
} 
increased by 5\%. Similarly, Snyder and Evans (2006) use a legislative change in the US Social Security system that unexpectedly lowered the benefits for people born after January 1, 1917-the so-called Notch generation. A comparison of 5-year mortality rates after the age of 65 for males born in the first quarter of 1917 and the last quarter of 1916 shows that the "Notch" generation had slightly lower 5 -year mortality rates than the previous cohort. The authors suggest that this countervailing finding is partly due to the fact that the people in the Notch cohort increased their post-retirement labor supply, which in turn had beneficial health effects through reduced social isolation. Frijters et al. (2005) take advantage of the fact that the German reunification in 1990 resulted in large income transfers to the East German population but not to West Germans. As the collapse of East Germany was unanticipated, the authors could attribute differences in health consequences between the two groups to the resulting increase in real income. The results show a significant, but small, positive effect of the income shock on health satisfaction.

The current paper contributes to the studies described above by using exogenous variation in inherited wealth, a variation created by repeal of the inheritance tax in Sweden in the end of 2004, to estimate the effect of wealth on health. It also adds to the literature by investigating responses in plausibly objective measures of health from medical records and social insurance registers.

\section{The Swedish inheritance tax and how it was unexpectedly repealed}

This section begins with a short description of taxation of inheritances in Sweden prior to the tax was repealed. This is to provide an understanding of the source of variation I use for identifying the causal effect of wealth on health. After that, I discuss the way in which the tax reform was proposed, passed, and implemented. The main point is that the decision to repeal the tax was largely unexpected and that the reform was rapidly enacted. This would imply that the affected population had limited incentives or abilities to react with regard to the reform before it was implemented.

\subsection{Taxation on inheritances before the reform}

Prior to December 2004, legal heirs and beneficiaries of wills in Sweden were subject to inheritance taxation according to the laws stipulated in the Inheritance and Gift Tax Ordinance (AGL). ${ }^{13}$ Inheritance taxation implies that the inheritance received by the heir constitutes the tax base. This differs from estate taxation under which the tax payment is calculated based on the total value of the deceased's estate. The inheritance tax, similarly, depended on the succession scheme of the relationship between the deceased and the heir. ${ }^{14}$ For

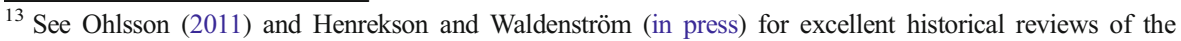
inheritance tax in Sweden.

${ }^{14}$ The law defined three classes of taxpayers. Class 1 contained the children and their descendants, and, before 2003, spouses and cohabiters. Class 2 constituted all other legal heirs, and Class 3 legal entities such as public institutions, charities, and foundations.
} 
the deceased's descendants (i.e., the deceased's children and their descendants), amounts exceeding a basic deductible exemption of SEK 70,000 were taxed according to a progressive tax schedule consisting of three marginal tax brackets in the amount of 10,20, and 30\%. Table 1 shows the tax schedule for the deceased's descendants. Based on the table, we see that $75 \%$ of inheritances fell below the exemption level and that the majority of the recipients liable for taxation were taxed at the lowest rate.

\subsection{The unexpected reform}

Concerned with mounting criticism of the inheritance tax, the Social Democratic government, in its Budget on September 20, 2004, announced that the AGL was to be repealed starting on January $1,2005 .^{15}$

The legislation had been criticized for complicating distributions of estates, especially those involving transfers of family firms. Escalating tax values on real estate in the early 2000 s had also resulted in public criticism of the inheritance tax, as many heirs, especially widows, found it difficult to afford the increasingly larger tax payments. Although the general impression was that the legislation was in need of a reform, the government's decision to completely abolish the tax came as a surprise (Silfverberg 2005). The tax on bequests to spouses had been abolished in January 2004, but at that time, there had been no indication of any plans to abolish the tax for other heirs (SOU 2003:3). As late as in June 2004, The Property Tax Committee had presented its final report Reform of inheritance and gift taxes (SOU 2004:66). This report did not propose a complete removal of the tax, but rather a series of adjustments to the existing rules. ${ }^{16}$ However, none of these were considered appropriate to implement at the time.

Unfortunately, there has been no systematic research undertaken on what contributed to the repeal of the inheritance tax (Henrekson and Waldenström in press). According to Silfverberg (2005), the government's "radical" decision to abolish the inheritance tax was probably a consequence of the Property Tax Committee's inability to review all of the rules in the AGL and work out a new modern legislation in time for the budget. According to Lodin (2009), that the decision fell on the inheritance tax and not on the wealth tax, which had also been heavily debated and evaluated by the Property Tax Committee, was a result of some horse trading between the Social Democrats and the Left Party. ${ }^{17}$

\footnotetext{
15 The main motivation was that it would be impossible to tackle the criticism of the tax with other legislative changes. It was also emphasized that the inheritance tax generated low revenues relative to its costly administration.

${ }^{16}$ The report had been preceded by several governmental studies on the Swedish tax system; none of which had proposed a complete repeal of the inheritance tax, but rather reductions of the tax rates and reforms of the valuation rules (see, for example, SOU 2002:52).

${ }^{17}$ According to Lodin (2009), Prime Minister Göran Person invited Left Party leader Lars Ohly to a private discussion, during which he demanded that Ohly agree to remove the inheritance tax and the wealth tax. Ohly refused to abolish both taxes, but after Person issued an ultimatum — one of the taxes would be removed in any case- Ohly agreed to remove the inheritance tax.
} 
Table 1 Tax rates on inheritances for the deceased's descendants

\begin{tabular}{llc}
\hline Taxable inheritance, SEK & Tax rate & $\begin{array}{l}\text { Share of inheritances falling } \\
\text { within the tax bracket }(\%)\end{array}$ \\
\hline $0-70,000$ & 0 & 75.1 \\
$70,000-370,000$ & $10 \%$ & 21.3 \\
$370,000-670,000$ & $30,000+20 \%$ within bracket & 2.4 \\
$670,000-$ & $90,000+30 \%$ within bracket & 1.2 \\
\hline
\end{tabular}

After the announcement of the repeal, things happened very rapidly. The Ministry of Finance worked out a memorandum bill, the Tax Agency and the Appeal Court in Stockholm gave their comments, and on December 16, only 3 months after the initial announcement, the bill was passed in Parliament. The Council of Legislation was critical of the quick manner in which the reform had been enacted and, in particular, of the limited preparation work that had preceded the bill. According to Silfverberg (2005), the swiftness of the legislative process was a contributing factor as to why the bill resulted in almost no political debate. ${ }^{18}$

The parliamentary decision on December 16 was that the AGL would expire at the end of 2004. However, out of concern for the bereaved relatives of the many Swedes who died in the Asian Tsunami on December 26, Parliament passed a law in April 2005 on inheritance tax exemption for the period of December 17-31, 2004, implying that the tax was affectively abolished on December 17.

A direct consequence of the repeal of the AGL is that inheritances from decedents who pass away after December 17, 2004 are exempted from taxation. Tax exemption also applies to inheritances that are received after December 17, but which originate from a previously deceased parent who died prior to the reform (the so-called postponed inheritances). However, if the tax liability occurred prior to December 17, the old law applies.

\section{Data}

In this section, the dataset is presented. ${ }^{19}$ In the first subsection, I describe the construction of the working study population. I also describe how I separate between individuals who were affected and unaffected by the tax reform and, in particular, how the heir's tax status is approximated using data on the deceased parent's net worth. The last subsection details the health outcomes used in the empirical analysis. These include hospitalization, the resulting diagnoses, insured sick leave, and mortality.

\footnotetext{
18 The limited debate that did take place mainly focused on the proposed date of repeal. The opposition parties argued that the tax should be abolished retroactively from 20 September 2004 (i.e., from the day when the government announced the proposal in the budget), as it would otherwise lead to an "inhuman situation" for heirs of decedents who would die in the last quarter of 2004. In its response, the government argued that this would result in an unfair outcome, as many (irreversible) cedes had already been made.

${ }^{19}$ Access to the data has been granted to the researchers at the Department of Economics at Uppsala University associated with project Intergenerationella överföringar: orsaker och konsekvenser [Intergenerational Transfers: Causes and Effects]. Due to its sensitive and confidential nature, the data cannot be exported from the closed server environment at Statistics Sweden.
} 


\subsection{The study population and approximation of tax status}

Information on individuals who received inheritances before and after the repeal of the inheritance tax is collected from the Belinda database, controlled by Statistics Sweden. ${ }^{20}$ Belinda covers information on the entire population of heirs and beneficiaries of deceased Swedes over the period of 2003-2005, approximately 960,000 individuals. I restrict my attention to heirs who have received inheritances from parents who were not married or partnered when they passed away and for whom an estate inventory report has been filed. ${ }^{21}$ These restrictions more or less follow the succession scheme default rules and yield a study population that is representative of the population of heirs in Sweden who receive parental bequests through a conventional estate division. ${ }^{22}$ To facilitate the econometric analysis, two additional restrictions have been imposed. First, it is required that the decedent had the same marital status (i.e., widow, never married, or divorced) at the time of death and 3 years prior. This requirement is needed for determining inheritance tax liability before and after the reform (see below for a more detailed discussion on this). Second, the heir is required to have received no more than one inheritance during the period of 2003-2005. This is to avoid confounding responses due to multiple inheritances. ${ }^{23}$

The main focus in the empirical analyses is on the heirs who were affected by the tax repeal, or, putting it differently, those with inheritances large enough to have resulted in a liability to pay the inheritance tax had the tax remained in effect. The Belinda database only contains information on monetary variables (e.g., estate size and inheritance amounts) for heirs who inherited before the tax reform. This implies that I am unable to directly observe which heirs received inheritances exceeding the tax threshold after the reform. My solution to this problem is to approximate the inheritances (and tax payments) of the heirs using data on the parent's net worth prior to the demise. Data on net worth is collected from the Swedish Wealth Register. Heirs for whom the inheritance, given by the product of the parent's net worth times the heir's share of the estate as dictated by the succession rule default, ${ }^{24}$ exceeds (is below) the tax threshold could be categorized as affected (unaffected) by the reform.

\footnotetext{
${ }^{20}$ See Elinder et al. (2014) for a more comprehensive description of the Belinda database and details on estates and inheritances in Sweden.

${ }^{21}$ The rule says that an estate inventory report should be filed for every Swedish citizen who passes away. Exemption is given for individuals who did not reside in or had any assets in Sweden. Exemption from the rule is also given to decedents whose assets are only sufficient to cover funeral expenses and do not comprise real estate. In the latter case, a so-called estate notification should be established.

${ }^{22}$ Children of married or partnered decedents are excluded because there is no, or only a partial, estate division and transfer to children when a married person passes away. These children are referred to as direct heirs with a postponed right to inherit as they have to wait for their last parent to pass away until they receive the inheritance from the first deceased parent. Thus, only children of widowed, divorced, or never married parents (i.e., whose deaths resulted in a conventional estate division) are included in the main analysis.

${ }^{23}$ The effects of the exclusion criteria on the size of study population are summarized in Appendix 1, Table 8.

${ }^{24}$ The inheritance share is calculated as one divided by the number of offspring appearing in the estate report (information that is available both before and after the tax reform). This implies that for a parent with two children and a net worth of 1 million SEK, each child will be recorded as having received 500,000 SEK $(1 / 2 \times 1,000,000 \mathrm{SEK})$. The assumption that the estate is divided in equal shares among the children is necessary, as I do not have information on estates and inheritances after the reform. While parents have the opportunity to divide the estate unequally among their children, a study by Erixson and Ohlsson (2014) using the same data as employed in the current paper reports that more than $90 \%$ of parents divide equally between their children.
} 
I calculate the inheritance values for heirs inheriting before and after the reform using the parent's net worth measured 3 years prior to the demise. This is to account for the possibility of differential incentives for tax planning (or evasion) having resulted in systematic differences in characteristics between heirs inheriting before and after the reform. ${ }^{25}$ To account for the possibility of economic conditions having affected the net worth for decedents dying on each side of the reform date differently, I adjust it with the annual official long-term central government borrowing rate. ${ }^{26}$ Moreover, as the inheritance law stipulates that heirs can never be forced to pay the debts of estates in deficit, negative net worth is replaced with the value zero. For each heir, I calculate the (gross) inheritance, referred to as imputed inheritance, as well as the corresponding tax payment (imputed tax payment) using the tax rates that applied before the reform (see Table 1). For deceased widows/widowers, the net worth commonly contains the inheritance of the previously deceased spouse, a so-called postponed inheritance, implying that the children of widowed parents effectively receive two inheritances. ${ }^{27}$ This is because married individuals with common children inherit each other in Sweden. When the first parent passes away, the children do not receive the money, as the inheritance is instead passed on to the surviving parent. Instead, they become entitled to a postponed right to the inheritance from the first parent. When the last parent eventually passes away, the children receive both inheritances. The surviving spouse is free to dispose the deceased's estate in whatever way she wants (except for bequeathing it) for the remainder of her life. Since the actions of the surviving spouse may affect the value of the deceased's estate, the law stipulates that the heir is entitled to a share of the first deceased parent's estate and not a specific amount.

To account for the fact both inheritances were subject to the deductible exemption, I divide the net worth of widows/widowers into two equally sized parts, which I then distribute evenly between their children. ${ }^{28}$ This is in accordance with the schematic distribution applied by the Tax Agency. I then subtract the deductible exemption (SEK 70,000 ) from each of the two inheritances before calculating the total tax payment.

To test how well the imputed tax payment corresponds to actual tax payment, I calculate the correlation between the two measures for heirs inheriting before the repeal of the tax. (i.e., in 2003 and 2004). The raw correlation is $0.842(p<0.01)$, suggesting that the imputed measure is a valid proxy for actual tax payment. I have data on inheritances for a representative sample of 3\% of heirs of decedents who died in 2005. The correlation between the two tax measures in this sample is almost identical to that

\footnotetext{
${ }^{25}$ Recent studies show that people engage in estate tax planning (or evasion), both during life and shortly before death, and that this behavior tends to be positively correlated with wealth (Joulfaian 2004; Nordblom and Ohlsson 2006; Kopczuk 2007).

${ }^{26}$ The estate value 3 years before death is calculated as Estate $t-3=$ Net $_{t-30 r t h}-3 *\left(1+i_{t-2}\right) *(1+$ $\left.i_{t-1}\right) *\left(1+i_{t}\right)$, where $i$ is the yearly official long-term central government borrowing rate and $t$ denotes the year of death. The is during the considered years were $5.34 \%$ (2000); $4.98 \%$ (2001); $5.15 \%$ (2002); $4.39 \%$ (2003); $4.30 \%$ (2004); and 3.24\% (2005). The results reported in the paper are robust to other rates of returns, both lower (the Swedish Riksbank's Repo rate) and higher (Real Estate Price Index and the rate of return at the Stockholm Stock Exchange).

${ }^{27}$ As the distribution depends on the deceased's marital status, I restrict the study population to heirs of decedents who had the same marital status (i.e., widow, never married, or divorced) at the time of death and 3 years prior.

${ }^{28}$ The default rule is that children to unmarried or divorced parents are entitled to the inheritance from the day when the parent passes away, or put differently, for these children, the concept of postponed inheritance does not apply.
} 
of heirs inheriting before the tax repeal $(0.837, p<0.01)$. Moreover, the share of heirs with positive tax payments is very similar across the years. In sum, these calculations suggest that the imputed measure is valid both within and across the inheritance cohorts and that it can effectively be used to decide the heirs' tax status.

In total, 79,801 heirs received inheritances above the tax threshold. They are the main focus of the empirical analysis, hereafter referred to as the main sample. However, heirs who received an inheritance below the tax threshold $(133,896)$ are not entirely omitted from the analysis. They are used in placebo experiments and in the estimation of wealth effects on mortality, hereafter referred to as the below tax threshold (BTT) sample.

\subsection{Health outcomes ${ }^{29}$}

The health outcomes in this paper are collected from three administrative registers: the Swedish National Patient Register, which contains detailed data on all hospital admissions concerning Swedish citizens (inpatient care), including data on diagnoses, the Integrated Database for Labour Market Research (LISA), which contains information on sick leave covered by the national sickness insurance ${ }^{30}$ exceeding 14 days, and the Cause of Death Register, which contains data on the date and cause of death for all Swedes who pass away. Below, I describe the health outcomes obtained from these data sources.

- Hospitalization is an indicator variable that takes value one if the individual has been hospitalized, for any cause, at least once during the year, and otherwise zero. The variable is available for each year over the period of 1993-2011 and for all individuals. It should be pointed out that hospitalization captures health conditions severe enough to require the medical and technical expertise of hospitals. ${ }^{31}$

- Diagnosis is represented by a set of indicator variables representing each of the 21 chapters in the WHO's International Statistical Classification of Diseases and Related Health Problems (ICD) (see Table 9, Appendix 1). More specifically, the indicator variables take value one if the individual, in the given year, has been hospitalized for any diagnosis appearing in the specific chapter, and otherwise zero. 32 The reason for using this categorization is twofold. First, there is not enough variation to provide reliable estimates with respect to specific diagnoses. Second, it solves the problem of tractability of diagnoses before and after the reform of the

\footnotetext{
${ }^{29}$ Relevant demographic and socioeconomic variables such as year of birth, gender, nationality, marital status, and education are collected from the Birth Register and the LISA database, whereas data on incomes and wealth are gathered from population registers provided by the Tax Agency. The Tax Agency collects the information directly from relevant sources, such as personal tax files for incomes and financial institutions and intermediaries for wealth. The variables are available for each year over the period of 1999-2009 (except wealth, which is available up to 2007).

${ }^{30}$ See Larsson (2006) and Hesselius et al. (2013) for informative reviews of the Swedish sickness insurance.

31 Treatment of less severe conditions, medical checkups, and other forms of preventive care is a matter for primary (outpatient) care. Since 2001, The Swedish Board of Health and Welfare keeps a register on outpatient care admissions. Unfortunately, these data are of quality for the study period and it is not recommended that these are used for research purposes.

${ }^{32}$ The physician is required to report the diagnosis (mapped into ICD code) for the disease or symptom for which the patient received treatment.
} 
ICD system in 1997, which replaced the previous ICD-9 system with the current system known as ICD-10. The diagnosis variables are available for each year over the period of 1993-2011, for all individuals, and are used for investigating the reasons for the hospital admissions. The focus is on the ten variables with the highest pre-inheritance period incidences, see Table 10 (and variables in italics in Table 9). The remaining variables are grouped into one variable called others.

- Sick leave is an indicator variable that takes value one if the individual has received sickness benefits for more than two consecutive weeks during the year, and otherwise zero. ${ }^{33}$ Sickness benefits are paid out by the compulsory national sickness insurance, covering all employees in Sweden, and are intended to compensate for lost income during illness that prevents the employee from doing her job. Sick leave could be considered an objective measure of health, since in order to receive sickness benefits, the individual has to send in a doctor's certificate to the Swedish Social Insurance Agency verifying that her reduced working capacity is a result of illness. ${ }^{34}$ The variable is available for each year over the period of 19932009 for the working-aged population (16-65 years) and works as a complement to hospitalization, as it also captures minor health conditions that are not severe enough to result in hospital admissions. A regression of hospitalization on sick leave yields a coefficient estimate of $0.51(p<0.001)$, implying that the outcomes are partially correlated. This is in accordance with previous studies reporting that medically certified sick leave is a good predictor of clinically defined bad health (Marmot et al. 1995; Kivimäki et al. 2003).

- Mortality is represented by six indicator variables (Mortality $1, \ldots$, Mortality6), which takes the value one if the individual dies from any cause, within 1 year up to within 6 years after the inheritance, respectively, and otherwise zero. The variables are available for all individuals. Mortality, similarly to sick leave, works as a complement to hospitalization, but captures the most severe state of bad health, namely death.

I have standardized hospitalization, diagnosis, and sick leave so that they are measured for the same number of years before (ten) and after (hospitalization, diagnosis-six; sick leave-four) the inheritance receipt for heirs inheriting in 2003, 2004, and 2005. Table 10 in Appendix 1 reports the annual incidences of the variables for the pre-inheritance years, as well as the share of heirs who die in any of the 6 years following the inheritance (Mortality6).

In order to establish that the empirical estimates in this paper are not artifacts of the current dataset, I estimate the cross-sectional relationship between wealth and health prior to the inheritance. The results, which are reported in Appendix 2, show that the

\footnotetext{
${ }^{33}$ For the first 14 days of a sick spell, the employee is entitled to sick pay, which is paid out directly by the employer. Data on sick pay is unfortunately not available.

34 The doctor's assessment of work ability is based on the individual's health status as well as his or her type of job. For example, for a bus driver, a broken leg automatically leads to sick leave for more than 2 weeks whereas a receptionist with the same condition is likely to be deemed work able before 2 weeks. However, severe conditions, such as acute myocardial infarction, severe stress disorder, and cancer (that requires continuous treatment), always lead to a sick spell lasting for more than 2 weeks. In practice, there is no limit for how long sickness benefits are paid out. Many sick spells continue for more than a year but some have even longer durations. However, the very long spells often lead to disability pension (which is not covered by sick leave) rather than to a return back to work (Hesselius et al. (2013).
} 
there is a statistically significant wealth gradient in hospitalization as well as in sick leave, implying that wealth is protective against bad health. ${ }^{35}$ This holds true both for the main sample and the BTT sample.

\section{Empirical strategies}

In this section, I present my empirical strategies for identifying the causal effect of the inheritance shock on the health outcomes discussed in the previous section.

A direct consequence of the repeal of the Inheritance and Gift Tax Ordinance is that offspring who received inheritances amounting to more than the basic deductible exemption from parents who passed away after December 17, 2004 experienced beneficial shocks to their inheritances equal in size to what their tax payments would have been had the parents passed away before that date.

The core of the empirical strategy is to estimate the causal effect of this inheritance shock on health by approximating the counterfactual outcome (i.e., health in the absence of the inheritance shock) in relation to the health experiences of heirs who received an inheritance above the tax threshold from parents who passed away before the reform date.

As it is essentially a random process determining whether an individual dies today or tomorrow, the ideal would be to compare the health of individuals whose parents passed away in close proximity to the reform. This approach would be similar in spirit to a regression discontinuity design framework, where the forcing variable would be the parent's date of death. However, due to the fact that only about 300 individuals die in Sweden each day, and even fewer with taxable estates, we would end up with a sample too small to provide enough power for statistical analysis in close proximity to the reform. ${ }^{36}$

To have any hope of being able to accurately detect differences in health between the two groups, I define heirs receiving inheritances above the tax threshold (main sample) after December 17, 2004 and in 2005 as being treated and heirs receiving inheritances above the tax threshold in 2004 (before December 17) and in 2003 as controls. Heirs receiving inheritances below the tax threshold (BTT sample) over these periods are referred to as "treated" (i.e., those inheriting after the tax repeal) and "controls" (i.e., those inheriting before the repeal).

Table 2 illustrates the variation in inherited wealth generated by the repeal of the inheritance tax by reporting descriptive statistics on inheritances and the corresponding inheritance shocks for the treated (and "treated") and the controls (and "controls"). The upper panel displays the statistics for the main sample, whereas the bottom panel displays the statistics for the BTT sample. It can be noted that the difference in size of the inheritances between the treated and the controls is small. This is reassuring, as it suggests that the inheritance shock is exogenous. ${ }^{37}$ A similar finding is noted for the

\footnotetext{
35 The reason for not estimating the wealth-mortality gradient is due to the fact that mortality is only observable in the period following the receipt of the inheritance, implying that it may be impacted by the inheritance receipt and the inheritance shock.

${ }^{36}$ I have tried a regression discontinuity approach using a bandwidth of 2 weeks (before and after the reform), but the resulting estimates of the wealth effect are too imprecise to be informative. This is not surprising, however, given that the estimation is only based on approximately 1500 observations.

${ }^{37}$ In Section 6, I confirm this further by showing that the treated and the controls are balanced in predetermined characteristics, including health.
} 
Table 2 Group means with respect to inheritances, inheritance shocks, and hospitalization (by time period), for main sample and BTT sample

\begin{tabular}{|c|c|c|c|c|c|c|}
\hline & \multirow[b]{2}{*}{ Inheritance $^{\mathrm{a}}$ (SEK) } & \multirow[b]{2}{*}{ Inheritance shock ${ }^{\mathrm{b}}$ (SEK) } & \multicolumn{4}{|c|}{ Hospitalization, by period ${ }^{\mathrm{c}}$} \\
\hline & & & Pre $(\%)$ & Post (\%) & Post-Pre (\%) & $N$ \\
\hline \multicolumn{7}{|l|}{ Main sample } \\
\hline Treated & 548,189 & 70,817 & 6.6 & 8.7 & 2.2 & 28,827 \\
\hline Controls & 565,417 & 0 & 6.7 & 8.6 & 2.0 & 50,950 \\
\hline \multicolumn{7}{|l|}{ BTT sample } \\
\hline “Treated” & 32,923 & 0 & 7.6 & 10.1 & 2.4 & 48,165 \\
\hline "Controls" & 34,671 & 0 & 7.8 & 10.1 & 2.3 & 85,967 \\
\hline
\end{tabular}

Dummy variables are reported in percent

${ }^{\text {a }}$ Refers to imputed inheritance, see Section 4

${ }^{\mathrm{b}}$ Approximated by imputed tax payment, see Section 4

${ }^{\mathrm{c}}$ The means have been calculated as yearly average over the given period

BTT sample. Regarding the inheritance shock (approximated by the imputed tax payment, see Section 4), it is, by definition, zero for the controls and positive for the treated subjects in the main sample and zero for both groups in the BTT sample. The mean of the shock for treated subjects in the main sample is SEK $70,817 .^{38}$

For health outcomes observable over time, before and after the inheritance receipt (i.e., hospitalization, diagnosis, and sick leave), I estimate the effect of the inheritance shock by comparing the difference in incidences before and after the inheritance for the treated subjects with the similar difference for the controls. The last three columns in Table 2 report descriptive statistics necessary for calculating these difference-indifferences (DID) with respect to hospitalization (i.e., the incidences in the pre- and post-periods, as well as the change in incidence over time (Post-Pre) for each group). It can be noticed that the pre-period incidences are similar across treated and controls. ${ }^{39} \mathrm{~A}$ comparison of the change in hospitalization (Post-Pre) between the treated and the controls suggests that the inheritance shock has a positive, albeit small, impact on the incidence, around 0.2 percentage points. The question, however, is whether or not we may interpret this impact as a causal effect?

To place this issue in perspective, one can compare the change in hospitalization over time across the "treated" and the "controls" in the BTT sample. In contrast to what we should expect to see given that both of these groups were unaffected by the tax reform, the implied DID is positive and indicates that the reform leads to a 0.1 percentage point increase in the outcome.

One possible explanation for this finding is that the DIDs obtained from Table 2 only account for biases from common trends in the outcome, such as health responses surrounding the death of the parent or an increasing trend in health over time, and not for the fact that the time periods over which the differences are calculated correspond to different calendar years for heirs inheriting before and after the tax

\footnotetext{
${ }^{38}$ See Table 13 in Appendix 3 for the distribution of the wealth shock.

${ }^{39}$ In Section 6, I present graphical evidence showing that the trajectories of hospitalization for the treated and the controls evolve similarly in the pre-inheritance period.
} 
reform. This could represent a problem given the fact that recent studies show that health tends to respond to temporary fluctuations in the economy (Ruhm 2000, 2003; Adda et al. 2009; Gerdtham and Johannesson 2005). The impact and severity of aggregate seasonal health shocks, such as the flu or the winter vomiting disease, may also differ between years. Although the influence of year-specific events is partially mitigated by using the average incidences for the pre- and post-periods, one may still be concerned by the possibility that the response in the outcome is the result of adverse events taking place in the years surrounding the reform or events taking place in a year in the beginning or in the end of the study period, rather than the inheritance shock. If, for instance, something adversely impacts the health of the treatment group in the last (calendar) year of the study period, we may incorrectly conclude that a difference in health across the two groups is a result of the inheritance shock. Likewise, an adverse event in 2004 would be picked up as a pre-period effect for the treatment group and as a post-period effect for the controls, implying that we may overestimate (underestimate) a positive (negative) effect of the inheritance shock.

My strategy for accounting for this source of bias is to estimate panel data models with cohort, time, and year fixed effects of the following form:

$$
H_{i, j, t, z}=\lambda_{j}+\lambda_{t}+\lambda_{z}+\phi D_{i} 1[j=2005: t \geq 0]+\varepsilon_{i, j, t, z},
$$

where $H_{i, j, t, z}$ is the outcome of individual $i$, of inheritance cohort $j(j=2003,2004$, 2005) at time since inheritance $t$, in calendar year $z \cdot{ }^{40} \lambda_{j}, \lambda_{t}$, and $\lambda_{z}$ are cohort, time, and calendar year fixed effects, respectively. $D_{i}$ is an indicator variable that takes the value one $(=1)$ from the year of the inheritance $(t=0)$ and onwards for individuals whose parents died after the tax reform $(j=2005)$, and zero $(=0)$ in all years for individuals whose parents died in the years before the reform $(j=2003,2004)$, and $\varepsilon_{i, j, t, z}$ is an idiosyncratic error. The coefficient $\phi$ is the DID estimator that captures the average effect of the inheritance shock over the years following the inheritance. To increase the precision of the DID estimate of the wealth effect, by reducing the variance of the error term, I also extend Model 1 with either a vector of observed predetermined individuallevel covariates or with individual fixed effects. ${ }^{41}$ The identifying assumption underlying these specifications is weaker than the one for the baseline specification. It now says that the counterfactual outcome, in the absence of treatment, is independent of treatment, conditional on covariates or individual fixed effects.

One issue with Model 1 is that it does not exploit the full extent of the variation in the treatment. Studying Table 13, in Appendix 3, shows that the inheritance shock varies substantially across the heirs in the treatment group and also that the distribution of the shock is highly skewed to the right. As the treatment indicator in Model 1 does not distinguish between treated individuals who experience large and small inheritance shocks, information about the strength of the treatment is not used, thus potentially making the estimation less precise. Moreover, as the majority of the treated subjects receive rather small inheritance shocks, which are expected to have a limited impact on health, Model 1 may produce understated estimates of the wealth effect.

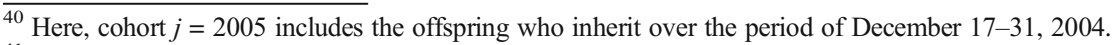

${ }^{41}$ As the individual fixed effects net out time-invariant factors at the individual level (including the cohort fixed effect, $\lambda_{j}$ ), I estimate the regressions with observable covariates and individual fixed effects separately.
} 
To address these issues, I exploit the continuous feature of the inheritance shock by estimating a model with an interaction between the treatment indicator in Model 1 and the natural logarithm $(\log )$ of the monetary value of the inheritance shock. This new model is referred to as Model 2. The main motivation for using the $\log$ of the inheritance shock is that health and the log of wealth are documented as being linearly related (see, for example, Ettner 1996; Smith 1999; Benzeval and Judge 2001). The usage of the log also simplifies the interpretation of the results as well as their comparability with previous studies, since the estimate could be interpreted as semi-elastic. The empirical specification of Model 2 looks as follows:

$$
H_{i, j, t, z}=\lambda_{j}+\lambda_{t}+\lambda_{z}+\theta D_{i} 1[j=2005: t \geq 0] \rho_{i, j, t, z}+\varepsilon_{i, j, t, z}
$$

where $\rho_{i, j, t, z}$ is the log of the inheritance shock. Hence, the interaction between $D_{i}$ and $\rho_{i, j, t, z}$ takes the log value of the inheritance shock for the treated subjects from $t=0$ and onwards, and zero for all periods for individuals in the control group. Consequently, the coefficient $\theta$ captures the continuous treatment effect over the years following the inheritance. Regarding $\lambda_{j}, \lambda_{t}$, and $\lambda_{z}$, these have the same interpretation as in Model 1. As for Model 1, I also estimate extended specifications of Model 2, including either individual-level covariates or individual fixed effects.

Unlike in Model 1, however, the heirs in the control group are not used directly for identifying the effect of the inheritance shock in Model 2 (since the inheritance shock is zero throughout this group), but are rather included to increase the precision of the estimates of the control variables. The identifying assumption underlying Model 2 is instead that the relationship between the health outcomes and the log of the inheritance shock would be the same for all values of the shock in the absence of the treatment. Or, putting it differently, for all levels of the log shock, the counterfactual trajectories of the health outcomes for the two groups should evolve similarly.

The fact that the heir has to be alive at the time of the inheritance to be included in the analysis means that the two previous models cannot be employed for estimating the effect of the inheritance shock on mortality. Instead, I estimate the wealth effect by comparing the difference in the likelihood of mortality between treated and controls in the main sample with the similar difference for heirs in the BTT sample. This alternative difference-in-difference strategy accounts for biases from time-invariant differences between the treated and the controls based on the assumption that environmental conditions (i.e., aggregate health shocks) during life, before the inheritance, have similar impacts on mortality rates for offspring receiving an inheritance above and below the tax threshold. ${ }^{42}$ Likewise, it accounts for differential annual trends in mortality based on the assumption that external exposures over the period after the inheritance have similar impacts on mortality for heirs receiving an inheritance above and below the tax threshold.

\footnotetext{
42 This DID strategy is similar in spirit to the one used by Snyder and Evans (2006), who estimate the effect of income on mortality by comparing mortality rates for men born in the first quarter of 1917 (the Notch cohort) with mortality rates for men born in the fourth quarter of 1916, using women of the same two birth quarters as controls.
} 


\section{Exogeneity of the inheritance shock and tests of identifying assumptions}

In this section, I present two informal tests of the identifying assumptions underlying the empirical strategy. The first test, which looks for differences in predetermined characteristics between the treated and the controls, suggests that the inheritance shock is exogenous. The second test compares the dynamics of hospitalization over the study period between the treated and the controls. Reassuringly, the trajectories evolve similarly in the pre-inheritance period, suggesting that the parallel trend assumption is satisfied. Taken together, the tests imply that any difference in health following the inheritance could reasonably be attributed to the inheritance shock.

\subsection{Test for differences in pre-determined characteristics between treated and controls}

Table 3 compares the means across the treated and the controls along with a number of different predetermined demographic and economic characteristics that are likely to be related to health. The first two columns report the means for the treated and the controls, respectively, and the last column (3) reports the $p$ values from $t$ tests of the difference in means between the groups.

By design, as indicated in Section 5, the treated and the controls inherit in different calendar years (2005 vs. 2003 and 2004). A direct consequence of this design is that the treatment group contains heirs of younger birth cohorts than the control group, as indicated by the difference in mean birth year between the two groups. What are some possible consequences of this with regard to other observable characteristics? It may be seen from column 3 that there are no statistically significant differences $(p>0.10)$ in the fraction women, fraction Swedish citizen, fraction with children in the household, fraction with lower secondary education, earned income, or net worth across the treated and the controls. ${ }^{43}$ The differences in observed characteristics that do exist are in age, fraction married, fraction with primary education, and fraction with upper secondary or postgraduate education. Although these differences are statistically significant $(p<0.10)$, they are quantitatively small and may easily be explained by the disparity in birth year between the two groups. It is generally acknowledged that younger cohorts tend to have higher education, be married to a lower degree, and receive inheritance later in life than older cohorts. The econometric models presented in Section 5 include inheritance cohort fixed effects, which should account for any unobserved heterogeneity related to birth cohort across the groups.

In Table 14, Appendix 4, I present similar descriptive statistics for the BTT sample. The differences in means between heirs inheriting before and after the reform are comparable to the corresponding differences for the main sample, again suggesting that unobservable (inheritance) cohort-specific factors have not manifested into persistent differences in observable health-related characteristics.

\footnotetext{
43 The means with respect to earned income and net worth have been calculated on the annual averages for the available pre-inheritance years to limit the influence of differential macroeconomic exposures. Moreover, earned income is adjusted for nominal wage growth in the public sector (base year 2004), and net worth is adjusted for inflation using CPI (base year 2004).
} 
Table 3 Comparison of group means, predetermined demographic and socioeconomic characteristics, treated, and controls, main sample

\begin{tabular}{lccc}
\hline & $\begin{array}{l}\text { Treated } \\
(1)\end{array}$ & $\begin{array}{l}\text { Controls } \\
(2)\end{array}$ & $\begin{array}{l}p \text { value 1-2 } \\
(3)\end{array}$ \\
\hline Birth year & 1951 & 1950 & 0.000 \\
Age when inheriting & 53.5 & 53.4 & 0.054 \\
Woman & 49.3 & 49.8 & 0.246 \\
Swedish citizen & 99.6 & 99.6 & 0.575 \\
Married & 55.9 & 57.3 & 0.000 \\
Children in household $^{\mathrm{a}}$ & 38.3 & 38.6 & 0.346 \\
Level of education $^{\mathrm{b}}$ & & & \\
$\quad$ Primary & 18.1 & 19.1 & 0.001 \\
$\quad$ Lower secondary & 42.6 & 42.6 & 0.939 \\
$\quad$ Upper secondary or postgraduate $^{\text {Earned income }}{ }^{\mathrm{c}}$ & 35.6 & 34.9 & 0.031 \\
Net worth $^{\mathrm{d}}$ & 274,891 & 274,062 & 0.577 \\
Number of obs. & 905,871 & 899,235 & 0.884 \\
\hline
\end{tabular}

Characteristics other than birth year, age, earned income, and net worth are measured 3 years before the inheritance receipt. Indicator variables are reported in percent

${ }^{a}$ Refers to children younger than 18

${ }^{\mathrm{b}}$ Highest achieved level of education

${ }^{c}$ The means are calculated on annual incomes (adjusted for the growth in nominal income, base year 2004) averaged over the available pre-inheritance years

${ }^{d}$ The means are calculated on annual net worth (adjusted to 2004 price level using CPI) averaged over the available pre-inheritance years

\subsection{Test for parallel trends in health}

Figure 1 displays the dynamics of hospitalization over the study period for the treated and the controls. Regarding the controls, I have separated between the heirs with respect to year of inheritance (2003 and 2004). The reason behind this division, rather than representing the dynamics for the controls using only one trajectory, is that it conforms better to Model 1, which includes controls for inheritance cohort. It should, however, be emphasized that the graphs display the unconditional means by time period and, hence, do not account for the fact that the periods correspond to different calendar years for the treated and the controls.

The general pattern is that the incidence of hospitalization is rather stable at the beginning of the study period, increases sharply around 2 years before the inheritance and continues to do so thereafter. The increasing trend is expected given that the heirs become older. The sharp rise surrounding the parent's death (vertical line) may reflect increased illness related to mourning and psychological distress (Scharlach 1991; Umberson and Chen 1994; Kessler 1997; Marks et al. 


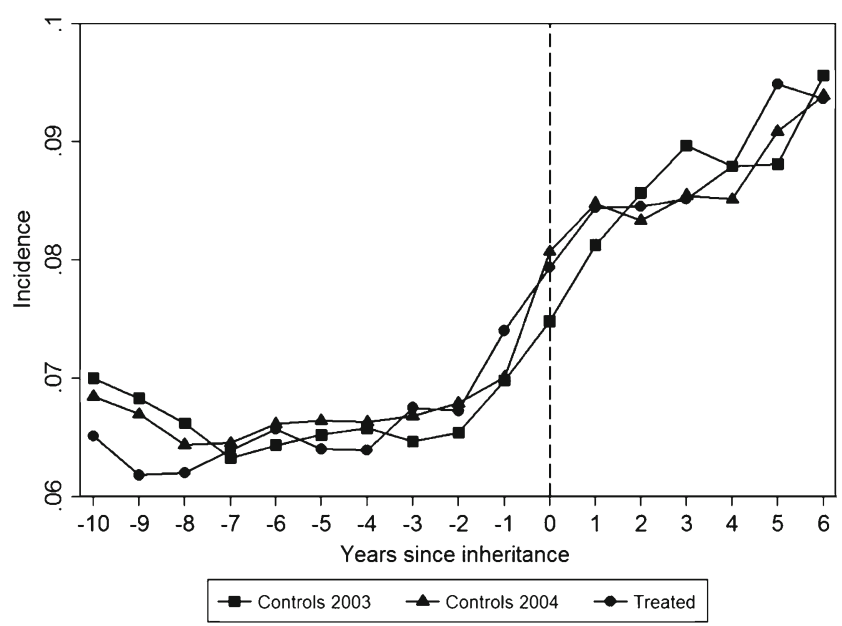

Fig. 1 The annual incidence of hospitalization for treated and controls, main sample. Note: the vertical line indicates the point in time when the inheritance is received. Controls 2004 does not include offspring receiving an inheritance from a parent during the period of December 17-31

2007; Rostila and Saarela, 2011), which is effectively accounted for by the econometric specifications. Regarding the trajectories of the treated subjects and the two control cohorts, these display similar trends in the pre-inheritance period, suggesting that cohort-specific influences have not resulted in persistent differences in health. The small differences in incidence between the groups that do exist could partially be explained by the fact that the years reported on the horizontal axis correspond to different calendar years for the groups (which is effectively accounted for by the year controls in the econometric specifications). The results nevertheless suggest that the parallel trend assumption is satisfied. In Section 7.6, I test for differences in the incidence of hospitalization in the pre-inheritance period between the treated and the controls in a regression framework. The result from this, more formal, test of the parallel trend assumption is in line with the graphical evidence.

It is, however, difficult to get an indication of whether or not the inheritance shock has any effect on hospitalization by comparing the trajectories over the post-inheritance years. If anything, the trajectory of the treated subjects appears to increase somewhat more sharply than those of the two control cohorts, but, as previously noted, one should be careful when interpreting this as a causal effect since differential year trends are unaccounted for.

In Fig. 2 in Appendix 4, I report similar graphs for the "treated" and the "controls" in the BTT sample. The parallel trend assumption appears to be satisfied for this group as well. Moreover, a comparison between Fig. 1 and Fig. 2 suggests that the heirs receiving inheritances above and below the tax threshold experience similar health dynamics, although the incidences differ somewhat in levels. To the extent that trends in mortality are similar to trends in hospitalization, this finding could be seen as supporting the identifying assumption underlying the estimation of wealth effects on mortality. 


\section{Results}

In this section, I present the empirical results. The first two subsections detail the results with respect to the effect of the inheritance shock on hospitalization estimated using Model 1 and Model 2 respectively. The estimates imply that the inheritance shock increases the likelihood of hospitalization for any cause by around $5 \%$. In the third subsection, I compare the impact of the inheritance shock to the impact of the inheritance as such and show that these are largely similar. The results from several placebo tests are discussed in Section 7.4, and these suggest that the main estimates could be interpreted as causal effects. Further support for this is reported in the fifth subsection, where the analysis is restricted to inheritances from sudden deaths. Section 7.6 reports results with respect to the dynamics of responses. In Section 7.7, I show that the effect is more pronounced for women, the relatively old, those with low education, and those receiving relatively large inheritances. The following subsection shows that a non-trivial share of the effect in hospitalization could be attributed to higher incidences of symptoms and signs of disease and cancer. In the final subsection, I present results suggesting that the inheritance shock does not have any detectable effects on sick leave or on mortality.

\subsection{The effect of the inheritance shock on hospitalization-Model 1}

The DID estimates of the effect of the inheritance shock on hospitalization reported in this section have been obtained from versions of Model 1 estimated using OLS. ${ }^{44}$ Given that hospitalization is binary, the estimates should be interpreted as the percentage point difference in the probability of the outcome between the treated and the controls. In connection to the regression estimates, I report the mean of the dependent variable (in brackets), in percent, for the post-inheritance period for the relevant control group. Dividing the DID estimate by this statistic gives the effect in percent. In each specification, the standard errors have been clustered at the individual level to account for correlation within the individual over time.

Column 1 in Table 4 reports the DID estimate obtained from Model 1 with only time controls. This is comparable to the naïve DID estimate implied by the statistics in Table 2. As expected, the estimate implies that the treated subjects have 0.2 percentage point higher probability of being hospitalized in the pre-inheritance period relative to the controls.

Column 2 reports the DID estimate from Model 1 with time and year controls. Similarly to the estimate in column 1 , the estimate is positive and statistically significant $(p<0.05)$ but, notably, almost twice as large $(0.43)$. This discrepancy suggests

\footnotetext{
${ }^{44}$ In Table 15 in Appendix 5, I show that the results reported in this sub-section and in the following are insensitive to the choice between the linear probability model and the (non-linear) Probit model: the marginal effects (calculated using the delta method) obtained from the Probit estimator as well as the accompanying standard errors are virtually the same as the coefficient estimates and the standard errors from the OLS regressions.
} 
Table 4 Difference-in-difference (DID) estimates, impact of inheritance shock on hospitalization (in percent), Model 1, main sample

(1)

\begin{tabular}{lllll}
\hline Effect $(\phi)$ & $0.222 * *(0.111)$ & $0.432 * *(0.218)$ & $0.433^{* *}(0.212)$ & $0.459^{* *}(0.210)$ \\
Mean of outcome & 8.63 & 8.63 & 8.63 & 8.63 \\
Effect in \% & 2.57 & 5.01 & 5.01 & 5.32 \\
Year FE & No & Yes & Yes & Yes \\
Covariates & No & No & Yes & Yes \\
Individual FE & No & No & No & Yes \\
$N$ & 79,801 & 79,801 & 79,801 & 79,801 \\
$N * T$ & $1,356,617$ & $1,356,617$ & $1,356,617$ & $1,356,617$ \\
\hline
\end{tabular}

Coefficient estimates are reported in percent. Standard errors (in percent) clustered at individual, in parentheses. Covariates in column 3 include gender, a second-order polynomial in age, marital status, presence of children, level of education, income, wealth, and baseline health, whereas covariates in column 4 include a second-order polynomial in age. Effect in \% is calculated as $($ Effect $(\phi) /$ Mean of outcome $) \times 100$

**Significant at the $5 \%$ level

that the treated and the controls experience differential year trends and that year controls indeed are essential. ${ }^{45}$

Column 3 reports the DID estimate from Model 1 augmented with a set of predetermined individual-level covariates that are standard in the literature, including gender, a second-order polynomial in age, marital status, presence of children, level of education, income, and wealth. ${ }^{46}$ The model also keeps baseline health constant by controlling for the total number of hospitalization episodes over the 4 years preceding the inheritance. This approach has previously been proven useful when it comes to accounting for sources of otherwise uncontrolled heterogeneity (Adams et al. 2003; Gardner and Oswald 2007; Kim and Ruhm 2012). The results indicate that the inclusion of controls changes the point estimate of the wealth effect and the standard error only with respect to the third decimal. ${ }^{47}$

\footnotetext{
${ }^{45}$ Since it was decided retroactively that inheritances received during the period of December 17-31, 2004, would be exempted from taxation, it may be a source of concern that anticipatory effects of heirs inheriting during this period are different from those of heirs inheriting after the reform. Reassuringly, however, the DID estimate is unchanged when I estimate the model on a sample without these individuals. Moreover, recent studies have documented that people may postpone their death to save taxes, see Eliason and Ohlsson (2013) and Kopczuk and Slemrod (2005). Regarding the current reform, Eliason and Ohlsson show that deceased individuals with taxable estates were more likely to have passed away on January 1, 2005, from when the tax was (supposed to be) repealed, rather than on December 31, 2004, compared to deceased individuals without taxable estates. To account for the possibility that individuals whose parents died during the days surrounding the reform are systematically different from other heirs, I have redone the main analyses omitting heirs inheriting during the 2 weeks following the reform. Reassuringly, the results from this exercise are similar to the main results.

${ }^{46}$ The covariates (except age) are measured in the period prior to the inheritance. This is to ensure that they are exogenous with respect to inheritance shock. Gender, marital status, education, and presence of children are measured 4 years before the receipt (the earliest available year), whereas income and wealth are included as the annual averages over the available pre-inheritance years in order to limit the influence of differential macroeconomic exposures across the treated and the controls. To account for concavity in the relationship between wealth or income and (good) health, I use the logarithm of one plus the variable value.

${ }^{47}$ The coefficients on the covariates (not reported) are generally statistically significant at conventional levels and have the expected sign.
} 
Column 4 reports the DID estimate from the model specification with individual fixed effects. It should be noted that the estimate of the wealth effect is largely similar to the estimates in columns 2 and 3, implying that any bias from unobserved heterogeneity across individuals (e.g., differences in genetics, time preferences, or early childhood exposures) is small. Moreover, the slight decrease in the standard error, as compared to the previous specifications, suggests that the efficiency gain from this extension of the model is trivial.

Taken together, the results in Table 4 suggest that the inheritance shock leads to a 5\% increase in the probability of hospitalization. Is this a large or a small effect? To get some perspective regarding this issue, I compute the cross-sectional relationship between age (in years) and hospitalization, as it is well known that age has a large impact on health. It turns out that the effect of the inheritance shock equals the impact of being about 4 years older, suggesting that the wealth effect is non-trivial. However, when I relate the wealth effect to the impact of education, another factor related to health status (Lleras-Muney 2005; Cutler and Lleras-Muney 2010), I find that having primary or lower secondary education, as compared to upper secondary or postgraduate education (i.e., the impact of having lower education), increases the probability of hospitalization by $18 \%$. This suggests that the effect on health of a $7 \%$ increase in wealth should be considered comparably small. ${ }^{48}$

\subsection{The effect of the inheritance shock on hospitalization-model 2}

Table 5 details the DID estimates obtained from Model 2. These estimates are reported in percent, and given the fact that the inheritance shock is in log, they provide the percentage point change in the probability of the outcome from a $1 \%$ inheritance shock.

In line with what I found in the previous section, the specification with only time effects (column 1) generates a point estimate that is positive and statistically significant at the $10 \%$ level. Turning to column 2 , it may be noted that the estimate from the specification with both time and year effects is larger in magnitude than the previous estimate, but also that it is statistically insignificant. The estimate as well as the standard error remains similar when I control for observable characteristics in column 3 .

In column 4 , however, we see that the DID estimate from the specification with individual fixed effects is positive and statistically significant $(p<0.05)$. The magnitude of the estimate implies that an inheritance shock of $1 \%$ increases the incidence of hospitalization by 0.03 percentage points, or $0.4 \%$ if compared to the post-period mean of the variable.

How does this finding compare to the finding in the previous section? Assuming that the effect is consistent across the two models, the estimate in column 4 suggests that a $7 \%$ increase in wealth (i.e., the average wealth increase due to the tax reform) increases the likelihood of hospitalization by $2.9 \%(7 * 0.4)$. While this response is somewhat lower than the one obtained from Model 1, it is nevertheless of the same order of magnitude. The level of significance is also similar across the two models $(p<0.05)$, thereby suggesting that there is no evident efficiency gain from exploiting the variation in shock size.

\footnotetext{
$\overline{48}$ One explanation for this is that education has been obtained early in life, meaning that its effect has had more time to accumulate into health.
} 
Table 5 Difference-in-difference (DID) estimates, impact of inheritance shock on hospitalization (in percent), Model 2, main sample

(1)

\begin{tabular}{lllll}
\hline Effect $(\theta)$ & $0.0187^{*}$ & 0.0310 & 0.0323 & $0.0417^{* *}$ \\
& $(0.0108)$ & $(0.0198)$ & $(0.0198)$ & $(0.0197)$ \\
& {$[8.63]$} & {$[8.63]$} & {$[8.63]$} & {$[8.63]$} \\
Year FE & No & Yes & Yes & Yes \\
Covariates & No & No & Yes & Yes \\
Individual FE & No & No & No & Yes \\
$N$ & 79,801 & 79,801 & 79,801 & 79,801 \\
$N^{*} T$ & $1,356,617$ & $1,356,617$ & $1,356,617$ & $1,356,617$ \\
\hline
\end{tabular}

Coefficient estimates are reported in percent. Standard errors (in percent) clustered at individual, in parentheses. Mean of dependent variable (in percent), post-inheritance period for control group, in brackets. Covariates in column 3 include gender, a second-order polynomial in age, marital status, presence of children, level of education, income, wealth, and baseline health, whereas covariates in column 4 include a second-order polynomial in age. *Significant at the $10 \%$ level; **significant at the $5 \%$ level

The conclusion that may be drawn from the results in Table 5 is that the positive response in hospitalization is increasing in relation to the size of the inheritance shock. This contrasts with the estimates of the gradient between wealth and health. In Table 12, in Appendix 2, I report the estimate of the inheritance shock alongside the estimate of the gradient (in the current study population) and this comparison shows that the $95 \%$ confidence intervals are far from overlapping, suggesting that the two estimates are statistically distinguishable from each other.

\subsection{A comparison between the effect of the inheritance shock and the effect of inheritance on health}

The results in the previous subsections show that the inheritance shock is associated with an increased likelihood of being hospitalized. A question that remains, however, is whether the estimated effect merely picks up the effect of additional inheritance.

I investigate this by controlling for the inheritance amount in the estimations of Model 1 and Model 2. Since I do not have information on inheritance for heirs of decedents who passed away after the tax repeal, I use the imputed inheritance (see Section 4.1). In Table 16 in Appendix 6, I report the results from estimations that control, separately, for the inheritance in level, log, as well as in the form of a thirdorder polynomial. $^{49}$ The estimates with respect to the inheritance shock are qualitatively and quantitatively similar to the main estimates, implying that the impact of the inheritance shock remains even when controlling for the underlying inheritance.

Despite the results reported previously, it is interesting to investigate if the impact of the inheritance shock could be interpreted as the effect of inheritance as such.

\footnotetext{
${ }^{49}$ More precisely, I estimate Model 1 and Model 2 with an additional variable that takes value zero in years prior to the year of the receipt and from there on the value of the inheritance (in either level, log or polynomial form), for the treated as well as for the controls.
} 
Estimating the inheritance effect is inherently difficult, however, since there is no obvious counterfactual. People who lose a parent but do not receive an inheritance, as the parent lacked wealth, are likely to differ from those who receive an inheritance. Moreover, a comparison of health responses between inheritors and individuals who do not lose a parent (and thus do not receive an inheritance) may be confounded by responses in health that are due to mourning and grief.

I propose two different strategies for resolving these issues. The first strategy (Strategy 1) exploits the fact that children of married couples do not receive an inheritance when the first parent passes away, but instead a postponed right to inherit (see Section 4.1). Children who receive a postponed inheritance right during the study period are included in the data and I use them as counterfactuals to those who do receive an inheritance in order to estimate the effect of receiving an inheritance on hospitalization. The estimation is essentially a difference-in-difference estimator that compares the incidence of hospitalization before and after the inheritance between heirs in the main sample (net of heirs inheriting in 2005, to avoid confounding impacts of the tax reform) and heirs with a postponed right (who would have received inheritances of equal sizes as the heirs in the main sample had they inherited today). ${ }^{50}$ The regression results are reported in Table 17 in Appendix 6 and these show that receiving an inheritance increases the likelihood of hospitalization by 1.7 percentage points, or compared to the baseline incidence, almost $25 \% .^{51}$ This is five times the effect size of $5 \%$ found in the main analysis. Given that the average value of inheritances in the treatment group is $548,000 \mathrm{SEK}$, or eight times the average inheritance shock, the expected effect size, if the relationship between inheritance and hospitalization would be linear, is $40 \%(5 \% * 8)$ rather than $25 \%$. However, while the result suggests that the effect of receiving an inheritance on hospitalization may be non-linear, the effect is in the same ballpark as the effect implied by the inheritance shock.

The second strategy (Strategy 2) exploits variation in timing of heirs who received an inheritance during the period of 2003-2004. ${ }^{52}$ More specifically, I compare the before-after change in hospitalization of the cohort of heirs who inherited in 2003 with the same before-after change among heirs in the 2004 cohort, who are identical, except that they inherit 1 year later. ${ }^{53}$ The counterfactual, in other words, is inheriting the next year rather than this year. ${ }^{54}$ The regression results are displayed in the second column in Table 17 in Appendix 6, and here we see that they are similar to those from the previous strategy in that the inheritance effect is positive and statistically significant. However,

\footnotetext{
${ }^{50}$ The counterfactual should thus not be thought of as a situation of no inheritance whatsoever, but rather inheriting later in time. This counterfactual is reasonable, since basically everyone goes through the process of inheriting at some point in life.

${ }^{51}$ Whether or not the results from the estimation could be interpreted as causal effects hinge on the assumption that the outcome would have evolved similarly in the absence of the inheritance. Figure 3 in Appendix 6 displays the dynamics of hospitalization over the study period for the two groups and here we see that the preinheritance (pre-parent loss) trends are fairly parallel, suggesting that the assumption is fulfilled.

${ }^{52}$ I restrict my focus to heirs in the main sample, excluding the 2005 cohort in order to avoid the impact of the tax repeal.

${ }^{53}$ A similar strategy is used by Elinder et al. (2016) to study the effect of inheritance on wealth inequality.

54 The identification assumption that needs to be fulfilled for the estimate to be consistent is that the outcome would have evolved similarly for the two cohorts had they not inherited. A visual comparison of the preinheritance trends suggests that the assumption is plausible, see Figure 4 in Appendix 6.
} 
the response is somewhat larger, 37\%, and, subsequently, more in line with the expected effect size of $40 \%$ implied by a linear relationship.

In sum, the results in this section suggest that the effect of the inheritance shock is largely similar to the effect of an inheritance as such. This is comforting as inheritances represent one of the most common increases in wealth that people experience in life.

\subsection{Placebo tests}

In this section, I present results of several placebo tests designed to establish whether the main estimates represent a causal relationship, and not just a spurious correlation.

I begin by estimating Model 1 on the BTT sample (Placebo test I). ${ }^{55}$ An insignificant response in hospitalization, or at least a DID estimate that is smaller in magnitude than the corresponding estimate for the main sample, should be considered as supporting the causal interpretation of the main estimates. The results are reported in the first column of Table 6 and these show that the coefficient estimate on the treatment indicator is positive but smaller than the main estimate and also statistically insignificant, suggesting that the repeal of the inheritance tax does not have an impact on the incidence of hospitalization of heirs receiving an inheritance below the tax threshold.

The second placebo test (II) tests for an impact of the reform among children who received a postponed right to inherit during the period of 2003-2005 (see Section 7.3 for a discussion). As these children did not receive an inheritance during this period, they should not be affected by the tax repeal. To test for this, I estimate Model 1 with the treatment indicator indicating children who received a postponed right to inherit following the tax repeal (i.e., in 2005). I restrict my focus to those who would have received inheritances of equal sizes as the heirs in the main sample had they inherited today. The results of this test are reported in column 2 and they show that the coefficient estimate on the indicator is negative and statistically insignificant, suggesting that the tax repeal does not offset any confounding effects.

The third placebo test (III) tests for differential responses in hospitalization between heirs in the main sample inheriting in 2003 and 2004 (i.e., before the reform). Since both of these cohorts were unaffected by the tax repeal, we should not expect to find a differential response in the outcome in the years following the inheritance. The test is carried out by estimating Model 1 with the treatment indicator indicating whether the individual inherits in 2004, as compared to in 2003. The coefficient on the treatment indicator could thus be interpreted as the effect of the reform in the counterfactual case that was implemented 1 year before the actual implementation. The results are presented in column 3 and here we see that the coefficient estimate on the indicator is negative (as opposed to positive in the main analysis) and statistically insignificant at conventional levels.

The results in this section can be seen as supportive evidence that the main estimates of the effect of the inheritance shock on hospitalization represent a causal relationship.

\footnotetext{
${ }^{55}$ As the estimation of Model 2 relies on variation in the size of the wealth shock, it is not possible to conduct placebo tests of the model, as the wealth shock is zero for all individuals in the BTT sample.
} 
Table 6 Placebo tests, impact of inheritance shock on hospitalization (in percent), Model 1

\begin{tabular}{llll}
\hline & Placebo test & & \\
& I & II & III \\
& $(1)$ & $(2)$ & $(3)$ \\
\hline Effect $(\phi)$ & 0.134 & -0.116 & -0.184 \\
& $(0.173)$ & $(0.193)$ & $(0.135)$ \\
Mean of outcome & 10.09 & 6.61 & 8.62 \\
Effect in \% & 1.33 & -1.75 & -2.13 \\
$N$ & 133,896 & 77,309 & 51,964 \\
$N^{*} T$ & $2,276,232$ & $1,314,253$ & 883,388 \\
\hline
\end{tabular}

Coefficient estimates are reported in percent. Standard errors (in percent) clustered at individual, in parentheses. The models include time, year, and individual fixed effects, in addition to a second-order polynomial in age. Effect in $\%$ is calculated as (Effect $(\phi) /$ Mean of outcome $) \times 100$

\subsection{Additional test of the exogeneity of the inheritance shock using sudden deaths}

The causal interpretation of the main estimates reported in Sections 7.1 and 7.2 hinges on the premise that the inheritance shock is exogenous. The results from the placebo tests reported in Section 7.4, as well as the results in Section 6, suggest that this is indeed the case and that the tax repeal approximates the ideal experiment of random assignment of additional inheritance fairly well. However, to further investigate the credibility of this assumption, I use data from the Cause of Death Register to identify children of parents who passed away suddenly and test for whether responses in this group differ from those in the main analysis. Adding the restriction that the death should have been sudden may be thought of as adding an additional natural experiment on top of the existing one, further strengthening the exogeneity of the inheritance shock. For instance, focusing on sudden deaths is likely to effectively account for any remaining unobservable differences between the treated and the controls that may be due to differences in estate planning among the decedents who passed away before and after the tax repeal. The classification of sudden deaths (natural and unnatural) follows the classification in Andersen and Nielsen (2011). ${ }^{56}$ Of the children in the main sample, $17 \%$ have parents who passed away suddenly and I use these children in estimations of Model 1 and Model 2. The results are reported in Table 18 in Appendix 7. The estimate in the first column, generated by Model 1, is statistically significant and positive, implying that the inheritance shock increases the likelihood of hospitalization. Whereas the effect is somewhat larger in size than the main estimate, it is of the same order of magnitude. ${ }^{57}$ The same goes for the estimate obtained from Model 2 (reported in column 2), but with the difference that it falls just above the $10 \%$ statistical significance level $(p=0.137)$.

\footnotetext{
$\overline{56}$ See Andersen and Nielsen (2011), Table 1. Natural sudden deaths are acute myocardial infarction, cardiac arrest, congestive heart failure, stroke, and sudden death by unknown cause. Unnatural sudden deaths are traffic accidents and other accidents and violence.

${ }^{57}$ The baseline incidence of hospitalization in this sub-population is $8.98 \%$.
} 
Taken together, the similarities between the estimates reported in this section and the main estimates may be viewed as further support for the empirical strategy and the causal interpretation of the main estimates.

\subsection{Dynamics of responses}

The results in Table 4 and Table 5 give us no sense of the dynamics of the wealth effect - whether it accelerates or stabilizes over time. To explore these dynamics, I estimate Model 1 and Model 2 with leads and lags of the treatment. More specifically, I include interactions between the treatment variable (discrete or continuous) and time dummies for each of years before the inheritance, the year of the receipt, and for each of the subsequent years. The results, reported in Table 7 , show that the coefficient estimates on the lead indicators from both models are statistically insignificant. This is comforting, as it suggests that the parallel trend assumption is indeed satisfied. As for the pattern of the lag structure, it shows that the difference in probability of hospitalization between the treated and the controls increases sharply at the time of the inheritance receipt. This could be viewed as additional support for the causal interpretation of the wealth effect. It should be noted, however, that the implied effect varies across the years and that it is only statistically significant for the second, third (only Model 2), and fifth years after the inheritance. In Table 19 in Appendix 8, I report results from the three placebo tests (described in Section 7.4) using the dynamic version of Model 1. Except for one lead indicator in the first test, the lead and lag estimates are statistically insignificant, a finding that further strengthens the belief in the main estimates.

\subsection{Heterogeneous responses}

In this section, I test for how the wealth effect varies with respect to socioeconomic characteristics.

Table 20 in Appendix 9 displays estimates of heterogeneous effects with respect to age, gender, and education, obtained from Model 1 (upper panel) and Model 2 (lower panel) with time, year, and individual fixed effects, in addition to a second-order polynomial in age.

The results show that the effect is markedly larger for old heirs (above the mean age of 53 years) than for young heirs (below the mean age). This finding corresponds with previous studies (see, for example, Lindahl 2005). Moreover, I obtain imprecisely measured DID estimates of the wealth effect when the population is limited to the working-age individuals (between 16 and 65 years) and the post-inheritance period is restricted to 4 years (to be comparable with the estimates with respect to sick leave). Although this finding may be a consequence of the shorter time period, it accords with the previous finding that the response in hospitalization is primarily driven by the relatively old.

The estimates from Model 1 suggest that the effect is primarily driven by women and not by men, whereas the estimates from Model 2 suggest that differences in responses across the sexes are negligible. ${ }^{58}$ Regarding education, the wealth effect is

\footnotetext{
58 The results show that women have a higher probability, relative to men, of being hospitalized both in the pre- and post-inheritance periods. This is consistent with previous research on gender differences in health (see for example Case and Paxson 2005).
} 
Table 7 Difference-in-difference (DID) estimates, impact of inheritance shock on hospitalization (in percent), dynamics of responses, Model 1 and Model 2, main sample

Model 1

Model 2

(1)

(2)

DID estimate by year since inheritance

\begin{tabular}{|c|c|c|}
\hline \multirow[t]{2}{*}{-8} & 0.0280 & 0.0240 \\
\hline & $(0.313)$ & $(0.0300)$ \\
\hline \multirow[t]{2}{*}{-7} & 0.0008 & 0.0134 \\
\hline & $(0.354)$ & $(0.0336)$ \\
\hline \multirow[t]{2}{*}{-6} & 0.0121 & 0.0203 \\
\hline & $(0.363)$ & $(0.0344)$ \\
\hline \multirow[t]{2}{*}{-5} & 0.0121 & 0.0206 \\
\hline & $(0.365)$ & $(0.0344)$ \\
\hline \multirow[t]{2}{*}{-4} & -0.0837 & 0.003 \\
\hline & $(0.368)$ & $(0.0347)$ \\
\hline \multirow{2}{*}{-3} & 0.181 & 0.0310 \\
\hline & $(0.370)$ & $(0.0350)$ \\
\hline \multirow[t]{2}{*}{-2} & 0.197 & 0.0322 \\
\hline & $(0.375)$ & $(0.0354)$ \\
\hline \multirow[t]{2}{*}{-1} & 0.253 & 0.0510 \\
\hline & $(0.388)$ & $(0.0367)$ \\
\hline \multirow[t]{2}{*}{0} & -0.145 & 0.0005 \\
\hline & $(0.398)$ & $(0.0376)$ \\
\hline \multirow[t]{2}{*}{1} & 0.595 & 0.0570 \\
\hline & $(0.406)$ & $(0.0383)$ \\
\hline \multirow[t]{2}{*}{2} & $0.956^{* *}$ & $0.111 * * *$ \\
\hline & $(0.410)$ & $(0.0389)$ \\
\hline \multirow[t]{2}{*}{3} & 0.671 & $0.0860 * *$ \\
\hline & $(0.411)$ & $(0.0389)$ \\
\hline \multirow[t]{2}{*}{4} & 0.501 & 0.0630 \\
\hline & $(0.415)$ & $(0.0394)$ \\
\hline \multirow[t]{2}{*}{5} & $0.947 * *$ & $0.0871 * *$ \\
\hline & $(0.421)$ & $(0.0398)$ \\
\hline \multirow[t]{3}{*}{6} & 0.458 & 0.0427 \\
\hline & $(0.892)$ & $(0.0703)$ \\
\hline & 79,801 & 79,801 \\
\hline$* T$ & $1,356,617$ & $1,356,617$ \\
\hline
\end{tabular}

Coefficient estimates are reported in percent. Standard errors (in percent) clustered at individual, in parentheses. The model specifications include year, time, and individual fixed effects, in addition to a second-order polynomial in age

**Significant at the $5 \%$ level; ***Significant at the $1 \%$ level 
positive and statistically significant for heirs with primary or lower secondary education and negative and statistically insignificant for heirs with upper secondary or postgraduate education. This finding is in line with previous research documenting that highly educated individuals have more knowledge about, and are better at avoiding and managing, harmful health effects than their peers with lower levels of education (Goldman and Smith 2002).

Models of health production, as well as previous empirical studies, suggest that the wealth effect should be increasing in relation to the size of the shock. When I explore this in more detail, by estimating the wealth effect separately for heirs receiving an inheritance within the first, second, third, and fourth quartiles of the distribution using the two models, I find that the effect is solely driven by heirs in the third quartile of the distribution (see columns 1-4 in Table 21, Appendix 9). While the lack of an effect of the shock for the two lowest quartiles may be a consequence of the shock being too small to have any implications, it is more difficult to explain why the largest shocks have no impact. Wealthy heirs, as compared to poor, tend to receive larger inheritances in absolute terms; however, as a fraction of their wealth, the inheritances are typically relatively small (Wolff 2002; Elinder et al. 2016). To investigate whether the inheritance shock matters more for the relatively poor than for the relatively wealthy, I test for heterogeneous responses across the distribution of the inheritance scaled by initial wealth. ${ }^{59}$ The results show that the effect is only evident for heirs in the third quartile of the distribution (see columns 5-8 in Table 21, Appendix 9). The lack of effect for the two bottom quartiles may again be explained by the insignificant importance of the shock. However, that the effect is only evident for the third and not for the fourth quartile is somewhat puzzling, but may indicate diminishing returns to wealth.

\subsection{Explaining the wealth effect on hospitalization}

Taken together, the results in the previous sections suggest that the inheritance shock leads to an increase in hospitalization. At a first glance, this finding suggests that increased wealth has detrimental effects on health. One should, however, keep in mind that hospitalization does not inform us about the reasons for the hospital admission. To place this issue in perspective, I therefore continue and test for heterogeneous responses across the diagnoses reported in connection with the hospital admissions. In this section, I report regression results for the effect of the inheritance shock on the diagnosis indicators detailed in Section 4.

Column 1 in Table 22 in Appendix 10 displays the discrete DID estimates obtained from Model 1 (with time, year, and individual fixed effects) estimated on the main sample. It is noticeable that there are only two outcomes for which the DID estimate is statistically significant $(p<0.05)$ : neoplasms and symptoms and signs. The estimate with respect to neoplasms implies that the inheritance shock leads to a nearly $14 \%$ increase in the probability of the outcome, whereas for symptoms and signs, the coefficient implies an increase of $16 \%$. Taken together, the two effects explain around $70 \%$ of the effect in hospitalization. The fact that there is no significant response in any other variable (neither in the single diagnosis variables nor in the variable others)

\footnotetext{
${ }^{59}$ Initial wealth refers to the gross wealth averaged over the 4 years preceding the inheritance. For individuals whose average gross wealth is zero, the ratio between the inheritance and wealth is given the value one.
} 
suggests that the wealth effect on hospitalization is operating solely through symptoms and signs and neoplasms. Moreover, estimates obtained from the three placebo tests, described in Section 7.4, are statistically insignificant with respect to both diagnoses, suggesting that the main estimates are causal (see Table 23 in Appendix 10). In column 2 , I report the DID estimates from Model 2 estimated on the main sample. These show a similar pattern, in terms of sign and level of significance, to the estimates from Model 1. In accordance with the previous comparison of the estimates from the two models, they are of the same order of magnitude in percentage terms (if evaluated relative to the average inheritance shock).

What do the responses in symptoms and signs and neoplasms tell us about the mechanisms through which wealth affects hospitalization?

The variable symptoms and signs, as indicated by the name, captures symptoms and signs of disease (e.g., irregular heart rate, shortness of breath, fever, senility, general feeling of illness), as well as unusual findings during medical examinations (e.g., blood and urine samples). ${ }^{60}$ Given that the condition has resulted in a hospital admission, the response in the variable may on the one hand imply that the inheritance shock leads to worse health, and potentially more so if we had studied the effects over a longer period of time. ${ }^{61}$ On the other hand, the response could be interpreted as if the shock has resulted in people being more prone to seek care for health irregularities, possibly to reduce the likelihood of more severe conditions in the future. This is in line with previous studies, which document that economic circumstances are positively associated with disease prevention (see, for example, Cawley and Ruhm, 2011).

Regarding neoplasm, it contains diagnoses of cancers at different stages of development (i.e., benign, potentially malignant, and malignant tumors). ${ }^{62}$ It is difficult to give an analytical explanation for why the inheritance shock causes an increase in the likelihood of cancer, especially since it is commonly considered an equal opportunity disease (Smith 2004). Although lifestyle factors such as smoking and drinking, which are reported to be positively related to improved wealth (Apouey and Clark 2015; Kim and Ruhm 2012), are linked to many types of cancers (e.g., lung, head and neck, pancreatic, liver, colon, gastric, see, for example, Kushi et al. 2012), it seems unlikely that an increase in these risk factors would manifest into a higher cancer incidence within a period of only 6 years. If the inheritance shock has caused people to smoke and drink more, we should rather expect to find responses in diagnoses that are more immediately related to these risk factors, such as injuries (e.g., alcohol poisoning), mental and behavioral disorders, diseases in the digestive system (e.g., liver cirrhosis), respiratory diseases (e.g., chronic obstructive lung disease), and circulatory diseases (e.g., coronary heart disease and stroke) (World Health Organization, WHO 2002). Moreover, previous

\footnotetext{
${ }_{60}$ The results remain similar when I exclude diagnoses due to abnormal clinical and laboratory findings (ICD10: R70-R99 and ICD-9: 790-799).

${ }^{61}$ Minor medical problems generally increase the likelihood of experiencing more severe health problems. This is commonly referred to as the "progressive nature of disease" (Smith 2005).

${ }^{62}$ I have analyzed the effect on the wealth shock on cancerous tumors (malignant) and other tumors (benign and potentially malignant) separately, but the estimates are imprecisely measured, probably because of insufficient variation (i.e., not enough non-zero observations) in the outcomes.
} 
studies report that improved wealth leads to reduced obesity (Lindahl 2005; Kim and Ruhm 2012) and improved mental well-being (Gardner and Oswald 2007; Apouey and Clark 2015). But, if the inheritance shock exploited here has led to reduced obesity or improved mental well-being, we should, if anything, expect to find a reduction in cancer incidences, and not an increase (Kushi et al. 2012; Chida and Steptoe 2008).

One possible though speculative explanation for the positive response in neoplasm is instead that the inheritance shock has led to more health care visits in general, as indicated by the results with respect to symptoms and signs, and that cancer, which would otherwise have remained undiagnosed or been diagnosed later, is detected and possibly treated earlier. Thus, the higher incidence of hospitalization does not necessarily mean that the inheritance shock has detrimental effects on health, but rather that it results in more preventative actions against future morbidity.

To investigate the plausibility of this explanation, I estimate the dynamics of the response in the two diagnoses using Model 1 and Model 2 augmented with leads and lags of the treatment, as in Section 7.6. This would be seen as supporting the explanation if the response in symptoms and signs precedes the response in neoplasm. The results from this exercise are reported in Table 24 in Appendix 10 and they show that the responses in the two diagnoses generally occur simultaneously (in the second, third, and fourth year following the inheritance). The exception is for Model 1, where there is a response in symptoms and signs already in the year of the receipt and no similar response in neoplasm. Although this finding could be viewed as supporting the explanation, it should be noted that there is a response in symptoms and signs (but not in neoplasms) also in the year prior to the receipt $(t=-1)$ and, subsequently, that one should be careful not to infer too much in this regard.

This pre-inheritance shock response in symptoms and signs also suggests that one should be careful in drawing the conclusion that the relationship between the diagnosis and the inheritance shock is causal. However, in Table 25, I report estimates for the dynamic impact of the inheritance shock on symptoms and signs for heirs whose parents passed away suddenly (and for whom the exogeneity assumption is likely to be more plausible), and these show that there is no pre-inheritance shock response suggesting that the relationship, in this sub-population, is causal. While this finding speaks in favor of the explanation that symptoms and signs is responsible for the response in hospitalization, one should interpret it cautiously as the underlying analysis is based on a subset of the main study population.

\subsection{The effect of the inheritance shock on sick leave and mortality}

In this section, I complement the previous analyses by investigating responses in outcomes capturing health events that are both less and more severe than those resulting in hospital admissions. More specifically, I estimate the effect of the inheritance shock on sick leave (less severe) and mortality (more severe).

Table 26 in Appendix 11 reports DID estimates from Model 1 and Model 2 with respect to sick leave. The models are estimated on heirs of working age in 
the main sample over a period of 10 years before and 4 years after the inheritance receipt. A comparison of the estimates from the models estimated with and without year fixed effects indicates that the treated and the controls experience differential year trends in the outcome. This is in line with what I found for hospitalization. In this case, however, the DID estimates from the preferred specifications of the models are all statistically insignificant, implying that the inheritance shock does not have any evident effect on the likelihood of sick leave. ${ }^{63}$ It should be noticed that I cannot rule out the possibility that the inheritance shock has consequences for health events captured by sick leave for heirs who are younger than 16 and older than $65 .{ }^{64}$ However, the fact that the wealth effect with respect to both sick leave and hospitalization is statistically insignificant for the working-age population lends additional support for the conclusion that the inheritance shock generated by the tax repeal has limited health consequences for the majority of the affected population. ${ }^{65}$

The impact of the inheritance shock on mortality is estimated by comparing the difference in the probability of dying over the post-inheritance period between treated and the controls in the main sample with the similar difference for the BTT sample (see Section 5). ${ }^{66}$ The regression results with respect to each of the six mortality indicators (i.e., Mortality1,..., Mortality6) are presented in Table 27, Appendix $11 .^{67}$ Neither the difference estimates (for any of the two samples) nor any of the DID estimates (which accounts for biases from time-invariant differences and year trends) are statistically significant at conventional levels. These results suggest that the inheritance shock has no detectable effect on mortality within any year over a period of 6 years after it occurs. ${ }^{68}$

\footnotetext{
${ }^{63}$ I have estimated Model 1, with sick leave as outcome, on the BTT sample (not reported), and the estimates are similar in terms of sign and statistical significance to the corresponding estimates for the main sample. However, the implied responses are quantitatively smaller.

${ }^{64}$ There is a literature studying the effects of inheritances on labor supply (e.g., Holtz-Eakin et al. 1993; Brown et al. 2010; Elinder et al. 2012; Bø et al. 2016). These studies generally find that inheritances lead to reductions in labor income and earnings as well as increased probability of retirement. The impact of inheritance as such on retirement should be accounted for by the empirical strategy since both the treated and the controls receive inheritance. What may be a concern, however, is if the inheritance shock has an impact on the decision to retire, as this may change the composition of the labor force and, subsequently, bias the estimates with respect to sick leave. I have analyzed this and the results (not reported) show that the inheritance shock increases the likelihood of retirement: the DID is positive (as expected) but statistically insignificant. I have also estimated the impact of the inheritance shock on labor earnings but although the effect has the expected negative sign, it is statistically insignificant.

${ }^{65}$ Table 12, in Appendix 2, shows that the 95\% confidence interval of the DID estimate of the wealth shock does not overlap with the corresponding interval for estimate of the gradient between sick leave and wealth. ${ }^{66}$ The analysis is based on heirs inheriting in the year before (2004) and in the year after the reform (2005). This is to limit the potential influence of confounding secular trends in mortality. However, I have redone the analysis including offspring inheriting in 2003, and I obtained largely similar results.

${ }^{67}$ The differences and the DID are estimated with linear probability models. The models include controls for age, age ${ }^{2}$, gender, marital status, presence of children, level of education, earned income, and net worth, measured 4 years before the inheritance, with the purpose of accounting for any remaining unobserved heterogeneity.

${ }^{68}$ The results in Section 7.8 suggest that cancer is detected earlier because of the wealth shock. It is, however, evident that this potentially preventative effect is not sufficient to have an effect on all-cause mortality, at least not over a period of 6 years. I have also tested explicitly for the impact of the wealth shock on the likelihood of cancer mortality within the 6-year period, but the estimate of the wealth effect is imprecisely measured.
} 


\section{Generalizability of the findings}

The treatment effects reported in Section 7 should be interpreted as the effect of additional inheritance on health. It should be noticed, however, that the inheritance shock under consideration is transitory (as opposed to, for example, a lottery winning yielding a monthly installment over many years or a permanent increase in retirement income) and relatively small. While this suggests that one should be careful when using the results for making conclusions about the relationship between permanent wealth and health, they provide knowledge about the wealth effects generated by policy changes of similar magnitudes as the repeal of the Swedish inheritance tax. This may be important from a policy perspective, as inheritance taxes of similar structures, in for instance Spain, the Netherlands, Belgium, Japan, France, and Germany, are currently up for debate. In Section 7.6, I also show that the effect of the inheritance shock is in line with the effect of inheritance as such, which is one of the most common shocks to wealth that people experience in life.

One should keep in mind, however, that as opposed to other wealth shocks, inheritances are associated with the demise of a parent, which may affect health in itself. ${ }^{69}$ Although the empirical strategy used for generating the main estimates effectively accounts for any confounding effects of bereavement, by comparing children who have all lost a parent, it is interesting to analyze whether parental loss has an impact on health. To estimate the bereavement effect, I exploit the fact that the heirs with a postponed right to inherit experience parental loss, but do not receive an inheritance. ${ }^{70}$ The identification strategy is built on the premise that I observe cohorts of heirs sequentially experiencing parental loss (but who do not receive an inheritance) over the time period of 2003-2005. By using this variation in the timing of parental loss, I effectively let the counterfactual be the development of health, measured by hospitalization and sick leave, in the cohorts experiencing parental loss 1 or 2 years later. ${ }^{71} 72$ The estimation results (reported in Table 28 in Appendix 12) show that parental loss has no detectable impact on hospitalization, but that it leads to a statistically significant increase in the incidence of sick leave of 0.791 percentage points, or $5.5 \%$ compared to the baseline incidence. These findings indicate that parental loss has implications for health (as suggested by previous studies), but not an extent that it leads to hospitalization.

How do the results in this paper correspond to those in the earlier literature? The arguably most closely related study is that of Cesarini et al. (2016), who

\footnotetext{
${ }^{69}$ Previous studies in social psychology and medicine report that losing a parent is associated with severe grief among adult children (Scharlach 1991; Umberson and Chen 1994; Kessler 1997; Rostila and Saarela, 2011; Marks et al. 2007) and a higher likelihood of depressive symptoms and increased consumption of antidepressant medicines (Schulz et al. 2003).

${ }^{70}$ In the analysis, I focus on heirs with postponed inheritances corresponding to the level of the receipts in the main sample.

${ }^{71}$ The reason for not studying the response in mortality is due to the fact that the identification strategy requires that the outcome is observable both before and after the demise of the parent.

${ }^{72}$ The identification assumption that needs to be fulfilled for the estimation strategy to yield consistent estimates is that the outcome would have evolved similarly for the cohort experiencing parental loss and the cohort(s) that are about to experience parental loss, in the absence of parental loss. Figures 5 and 6 in Appendix 12 display the trajectories of hospitalization and sick leave, respectively, by cohort. For both outcomes, the trajectories appear to be parallel in the period prior to the loss, suggesting that the parallel trend assumption is fulfilled.
} 
test for the impact of lottery winnings on health using Swedish administrative data. In line with the current paper, they find no evidence of an impact of wealth on mortality. The authors also test for the impact of lottery winnings on the probability of hospitalization. The definition of hospitalization that is the most comparable to mine is hospitalization for any cause within 5 years. The estimate with respect to that outcome is positive for their main population, similar to my estimate (from Model 1), but comparably smaller in magnitude and statistically indistinguishable from zero. The lottery winnings in Cesarini et al. are scaled in millions of SEK, which is 14.3 times the average inheritance shock in my study. Thus, multiplying my estimate by this factor yields an effect size of 6.6 percentage points (standard error of 3). This is an order of magnitude larger than the main estimate of Cesarini et al. (0.39 percentage points). ${ }^{73}$

What could explain the discrepancy in estimates with respect to hospitalization? Let us first assume that both estimates are correct. The results reported in Section 7.8 suggest that the increase in hospitalizations may be due to preventive actions. The fact that the subjects in my study are comparably younger and healthier, and are thus likely to benefit relatively more from engaging in prevention than the subjects in Cesarani et al., may then be a possible explanation. ${ }^{74}$ However, if one takes a more critical attitude towards my study, the explanation may simply be that it lacks the statistical power to detect an effect size in line with the, arguably, precise one in Cesarini et al. (2016). ${ }^{75}$ The standard error of my main estimate is indeed relatively large, which may be due to a combination of a comparably small treatment and sample size, implying that there is a fair chance that the true effect is substantially smaller. Given that the $95 \%$ confidence interval ( 0.72 to 12.48$)$ overlaps partly with the corresponding interval in Cesarini et al. ( -0.82 to 1.60$)$, one cannot, in the end, rule out the possibility that the estimates are similar. $^{76}$

\section{Concluding discussion}

In this paper, I exploit the exogenous variation in inheritance induced by the unexpected repeal of the Swedish inheritance tax to test for the impact of increased wealth on health outcomes commonly found in administrative registers.

\footnotetext{
${ }^{73}$ My estimate is in the ballpark of the upper bound of the $95 \%$ confidence intervals of the estimates obtained for some of the sub-populations in their study (see Tables AXIX-AXX in Online Appendix for Cesarini et al. (2016)).

${ }^{74}$ One should note, however, that the lottery players in Cesarini et al. (2016) appear to be more representative of the Swedish population at large (conditional on age and sex) than are the heirs in my study.

75 If I follow the calculations in Gelman and Carlin (2014), assuming that the estimate of 0.39 in Cesarini et al. (2016) represents the true effect size, the power of my study to detect a similar effect size at the $95 \%$ level (conditional on my estimate being statistically significant) is $5.5 \%$.

76 The fact that studies using lottery winnings and inheritances tend to deliver similar results with respect to other outcomes, such as labor supply (Imbens et al. 2001; Cesarini et al. 2015; Bø et al. 2016; Elinder et al. 2012) and investment decisions (Briggs et al. 2015; Andersen and Nielsen 2011), suggests that it is unlikely that the discrepancy in findings is a consequence of people treating lottery winnings and inheritances differently, as suggested by Winkelmann et al. (2010).
} 
The empirical analysis shows that the favorable inheritance shock resulting from the tax reform has limited consequences for objective health over a period of 6 years following the shock. The wealth effects are clearly distinguishable from the graded relationship between wealth and health in the cross-section, a finding that is in line with what has been documented previously in the literature. If anything, it appears as if the inheritance shock leads to more hospitalizations for symptoms of disease as well as cancer. One possible, though speculative explanation for this, perhaps unintuitive finding is that good health is necessary for enjoying the improved consumption prospects and that people therefore react more to minor health contingencies, which in turn result in the early detection and potential treatment of cancer. However, to investigate this further and, in particular, to pinpoint when in time cancer is initially discovered, one would like to complement the analysis with data on outpatient care but, unfortunately, such data not available for the study period.

Although the wealth shock exploited in this paper is received by people who have suffered the loss of a parent-who may therefore be unhealthier than the general population - the results generalize to people who are in their fifties, as the death of a parent commonly occurs at this stage of life. The fact that I can replicate the stylized facts concerning the cross-sectional relationship between wealth and health also suggests that the empirical results are not specific for the current sample. Moreover, the similarity between the impact of the inheritance shock and the impact of the inheritance as such broadens the generalizability of the results further.

It should be noted, however, that I could not rule out the possibility that potential effects of the inheritance shock take more than 6 years for materializing with regard to health. From a policy perspective, the results nevertheless seem particularly relevant, suggesting that wealth changes that might be expected from tax reforms of similar magnitudes as the repeal of the Swedish inheritance tax, affecting the middle aged, are unlikely to have any short or medium run consequences for health. The results, moreover, suggest that the redistribution of economic resources is unlikely to be an efficient strategy for reducing inequalities in health within this age group.

Acknowledgements I would like to thank Henry Ohlsson and Mikael Elinder for their support and encouragement. Valuable comments and suggestions from the editor, three anonymous referees, Adrian Adermon, Mikael Lindahl, Matthew Lindquist, Eva Mörk, Katarina Nordblom, Mattias Nordin, Håkan Selin, and Erik Spector, in addition to seminar participants at the Research Institute of Industrial Economics (IFN) and Uppsala University, are gratefully acknowledged. Sebastian Escobar provided excellent research assistance. Some of the work was carried out when I enjoyed the hospitality of the Department of Economics, Columbia University. Financial support from the Jan Wallander and Tom Hedelius Foundation is gratefully acknowledged.

\section{Compliance with ethical standards}

Funding This study was funded by a grant from Jan Wallander and Tom Hedelius Foundation (grant number: P2013:0101:1).

Conflict of interest The author declares that he has no conflict of interest. 


\section{Appendix 1. Additional description of data}

Table 8 Exclusion criteria and study population

Total number of heirs and other recipients of transfers at death 2003-2005

956,058

Exclusion criteria

(1) Relationship other than child

485,681

(2) Parent married or partnered at death

347,676

(3) No estate inventory report

61,405

Fulfills any of (1)-(3)

716,244

Remaining population

(4) More than one inheritance during 2003-2005

(5) Parent's marital status in $t$ not the same as in $t-3$

Fulfills any of (4)-(5)

Study population

Inheritance liable to taxation (main sample)

Inheritance not liable to taxation (BTT sample)

$t$ year of inheritance, $t-33$ years before inheritance

Table 9 Diagnosis variables, corresponding ICD chapters, and ICD codes (by version)

\begin{tabular}{|c|c|c|c|}
\hline Variable & ICD chapter & ICD-10 & ICD-9 \\
\hline Infections & I. Certain infectious and parasitic diseases & A00-B99 & 001-139 \\
\hline Neoplasms & II. Neoplasms & $C 00-D 49$ & $140-239$ \\
\hline Blood & $\begin{array}{l}\text { III. Diseases of the blood and blood-forming organs and certain } \\
\text { disorders involving the immune mechanism }\end{array}$ & D50-D89 & $280-289$ \\
\hline Endocrine & IV. Endocrine, nutritional and metabolic diseases & E00-E89 & $240-279$ \\
\hline Mental & V. Mental and behavioral disorders & F01-F99 & $290-319$ \\
\hline Nervous & VI. Diseases of the nervous system & $G 00-G 99$ & $320-389$ \\
\hline Eye & VII. Diseases of the eye and adnexa & $\mathrm{H} 00-\mathrm{H} 59$ & $360-379$ \\
\hline Ear & VIII. Diseases of the ear and mastoid process & H60-H95 & $380-389$ \\
\hline Circulatory & $I X$. Diseases of the circulatory system & $100-199$ & $390-459$ \\
\hline Respiratory & $X$. Diseases of the respiratory system & J00-J99 & $460-519$ \\
\hline Digestive & XI. Diseases of the digestive system & K00-K94 & $520-579$ \\
\hline Skin & XII. Diseases of the skin and subcutaneous tissue & L00-L99 & $680-709$ \\
\hline Musculoskeletal & XIII. Diseases of the musculoskeletal system and connective tissue & M00-M99 & $710-739$ \\
\hline Genitourinary & XIV. Diseases of the genitourinary system & $N 00-N 99$ & $580-629$ \\
\hline Pregnancy & XV. Pregnancy, childbirth and puerperium & O00-O99 & $630-676$ \\
\hline Perinatal & XVI. Certain conditions originating in the perinatal period & P00-P96 & $760-779$ \\
\hline Congenital & $\begin{array}{l}\text { XVII. Congenital malformations, deformations and chromosomal } \\
\text { abnormalities }\end{array}$ & Q00-Q99 & $740-759$ \\
\hline $\begin{array}{l}\text { Symptoms and } \\
\text { signs }\end{array}$ & $\begin{array}{l}\text { XVIII. Symptoms, signs and abnormal clinical and laboratory } \\
\quad \text { findings, not classified elsewhere }\end{array}$ & $R 00-R 99$ & $780-799$ \\
\hline Injury & $\begin{array}{l}\text { XIX. Injury, poisoning and certain other consequences of external } \\
\text { causes }\end{array}$ & S00-T88 & $800-999$ \\
\hline External & XX. External causes of morbidity & V00-Y99 & E01-E99 \\
\hline Factors & $\begin{array}{l}\text { XXI. Factors influencing health status and contact with health } \\
\text { services }\end{array}$ & Z00-Z99 & V01-V82 \\
\hline
\end{tabular}

Variables in italics refer to the ten symptoms with highest incidences in the study population 
Table 10 Health outcomes and incidences, in percent
${ }^{a}$ Incidence calculated as annual average over the 10 years prior to the inheritance

${ }^{\mathrm{b}}$ The incidence is calculated for the working-age population (16-65)

\begin{tabular}{lc}
\hline Health outcome & Incidence \\
\hline Hospitalization $^{\mathrm{a}}$ & 6.65 \\
Diagnosis $^{\mathrm{a}}$ & \\
Neoplasms & 0.55 \\
Mental & 0.57 \\
Nervous & 0.26 \\
Circulatory & 0.77 \\
Respiratory & 0.31 \\
Digestive & 0.78 \\
Musculoskeletal & 0.52 \\
Genitourinary & 0.53 \\
Symptoms & 0.84 \\
Injury & 0.73 \\
Others & 0.79 \\
Sick leave & 13.3 \\
Mortality6 & 3.51 \\
\hline
\end{tabular}

\section{Appendix 2. Cross-sectional estimates of the wealth-health gradient}

This appendix shows that the dataset may reproduce the positive cross-sectional link between wealth and health documented in the previous literature. It also reports estimates of the effect of inheriting with regard to health outcomes.

Table 11 presents estimates of the health-wealth gradient generated by linear probability models with hospitalization and sick leave as dependent variables and wealth as explanatory variable. To account for the fact that the relationship between wealth and (good) health is documented to be concave (see, for example, Ettner 1996; Smith 1999; Benzeval and Judge 2001), I use the logarithm of wealth. As negative values are not accommodated by the logarithmic function, I use the individual's gross wealth (i.e., the sum of real and financial assets, at market prices) rather than net worth. To incorporate observations with zero gross wealth in the estimations, I use the logarithm of one plus the amount of wealth in SEK. The models also include controls for a second-order polynomial in age, gender, marital status, presence of children, and level of education, as these have been used in the previous literature, as well as controls for year of inheritance. The outcomes as well as the covariates are measured 3 years before the inheritance receipt to assure that they are exogenous with respect to the tax reform. Columns 1 and 2 report the result with respect to hospitalization and sick leave for the main sample, whereas columns 3 and 4 report the corresponding results for the BTT sample. Regarding the main sample, the coefficient estimate on wealth is statistically significant at the $1 \%$ level, indicating that higher wealth reduces the likelihood of hospital admission. Divided by the sample mean, the estimate implies that a $1 \%$ increase in wealth, all else equal, reduces the likelihood of hospitalization by $4 \%$. Similarly, the coefficient estimate on wealth from the specification with sick leave as dependent variable is statistically significant $(p<0.01)$. The estimate implies that a $1 \%$ increase in wealth reduces the probability of the outcome by $2 \%$. The 
results for the BTT sample display a similar pattern as those for the main sample: the coefficient estimates on wealth are negative and statistically significant on conventional levels for both outcomes.

Table 11 Linear probability estimates (in percent) of the cross-sectional relationship between wealth and hospitalization and wealth and sick leave, main sample, and BTT sample

\begin{tabular}{lllll}
\hline & Main sample & & BTT sample \\
Outcome & Hospitalization & Sick leave & & \\
& $(1)$ & $(2)$ & $\begin{array}{l}\text { Hospitalization } \\
(3)\end{array}$ & Sick leave $^{\mathrm{a}}$ \\
\hline $\log (1+$ gross wealth $)$ & $-0.290^{* * *}$ & $-0.428^{* * *}$ & $-0.323 * * *$ & $-0.421^{* * * *}$ \\
& $(0.028)$ & $(0.041)$ & $(0.019)$ & $(0.030)$ \\
Mean of outcome & 6.82 & 15.95 & 8.00 & 18.85 \\
$N$ & 77,199 & 60,921 & 130,171 & 93,246 \\
\hline
\end{tabular}

Robust standard errors (in percent), in parentheses. The specifications include control variables, measured 3 years before the inheritance. These are age, age ${ }^{2}$, gender, marital status, presence of children, and level of education. The specifications also include controls for year of inheritance

$* * *$ Significant at the $1 \%$ level

${ }^{a}$ The specification has been estimated on the working-aged population (16-65)

Table 12 Estimates of the impact of inheritance shock and the gradient, in percent, main sample

\begin{tabular}{lll}
\hline Outcome & $\begin{array}{l}\text { Hospitalization } \\
(1)\end{array}$ & $\begin{array}{l}\text { Sick leave } \\
(2)\end{array}$ \\
\hline Effect & $0.042[0.003,0.080]$ & $0.026[-0.043,0.095]$ \\
Gradient & $-0.290[-0.345,-0.235]$ & $-0.428[-0.509,-0.347]$
\end{tabular}

Effect and gradient are reported in percent and 95\% confidence intervals (in percent) are in brackets. The effect specifications are estimated with Model 2 (see text) and include controls for a second-order polynomial in age. The gradient specifications include controls for a second-order polynomial in age, gender, marital status, presence of children, level of education, and year of inheritance

${ }^{\mathrm{a}}$ The specification has been estimated on the working-aged population (16-65)

\section{Appendix 3. Sample distribution of inheritance shock, treated subjects, main sample}

Table 13 Distribution of inheritance shock, treated subjects, main sample

\begin{tabular}{llllllllll}
\hline Mean & p5 & p10 & p25 & p50 & p75 & p90 & p99 & Sd & Count \\
\hline 70,817 & 1176 & 2533 & 7323 & 20,046 & 50,930 & 150,676 & 769,817 & 358,073 & 28,827
\end{tabular}

Inheritance shock is approximated by imputed inheritance tax payment (see Section 4 for description) 


\section{Appendix 4. Sample characteristics, BTT sample}

Table 14 Comparison of sample means, predetermined demographic and socioeconomic characteristics, and "treated" and "controls", BTT sample

\begin{tabular}{|c|c|c|c|}
\hline & $\begin{array}{l}\text { "Treated" } \\
\text { (1) }\end{array}$ & $\begin{array}{l}\text { "Controls" } \\
\text { (2) }\end{array}$ & $\begin{array}{l}p \text { value } 1-2 \\
\text { (3) }\end{array}$ \\
\hline Birth year & 1950 & 1949 & 0.000 \\
\hline Age when inheriting & 54.8 & 54.7 & 0.234 \\
\hline Woman & 49.9 & 49.7 & 0.423 \\
\hline Swedish citizen & 99.4 & 99.4 & 0.330 \\
\hline Married & 56.2 & 58.1 & 0.000 \\
\hline Children in household $^{\mathrm{a}}$ & 32.8 & 33.5 & 0.018 \\
\hline \multicolumn{4}{|l|}{ Level of education ${ }^{\mathrm{b}}$} \\
\hline Primary & 27.8 & 30.0 & 0.001 \\
\hline Lower secondary & 45.9 & 45.2 & 0.008 \\
\hline Upper secondary or postgraduate & 22.8 & 21.6 & 0.031 \\
\hline Earned income ${ }^{c}$ & 242,410 & 240,805 & 0.062 \\
\hline Net worth ${ }^{\mathrm{d}}$ & 488,363 & 470,437 & 0.024 \\
\hline Number of obs. & 48,165 & 85,970 & \\
\hline
\end{tabular}

Characteristics, other than birth year, age, earned income, and net worth, are measured 3 years before the inheritance receipt. Indicator variables are reported in percent

${ }^{a}$ Refers to children younger than 18

${ }^{\mathrm{b}}$ Highest achieved level of education

${ }^{c}$ The means are calculated on annual incomes (adjusted for the growth in nominal income, base year 2004) averaged over the available pre-inheritance years

${ }^{d}$ The means are calculated on annual net worth (adjusted to 2004 price level using CPI) averaged over the available pre-inheritance years

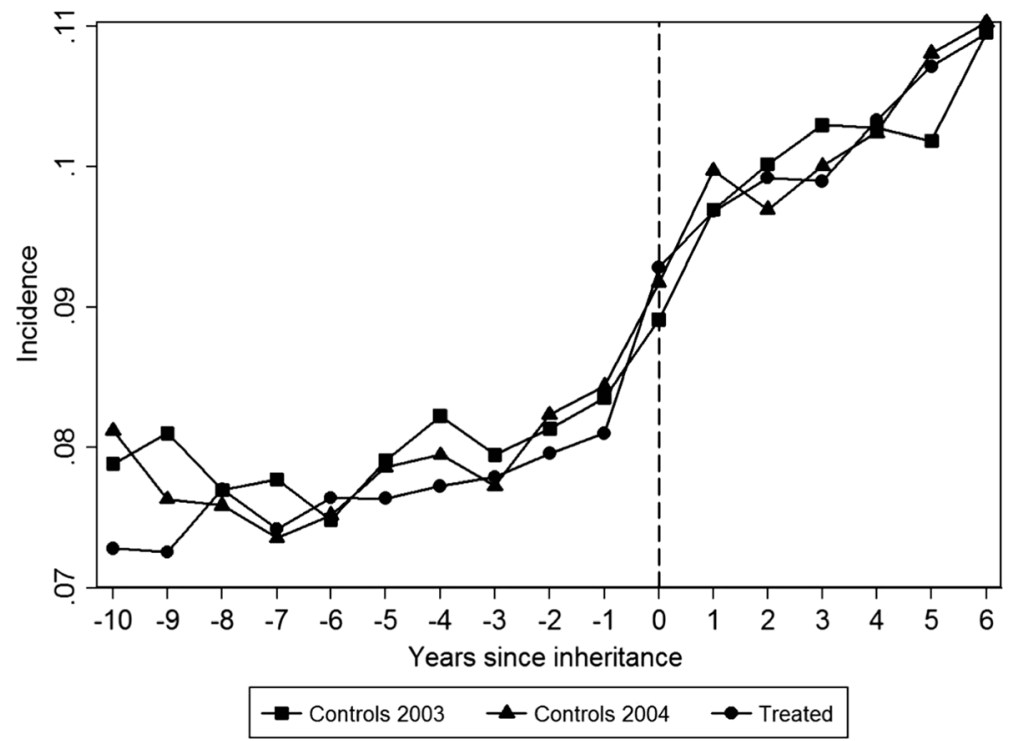

Fig. 2 The annual incidence of hospitalization for "treated" and "controls," BTT sample. Note: the vertical line indicates the point in time when the inheritance is received. Controls 2004 does not include offspring receiving an inheritance from a parent over the period of December 17-31 
Appendix 5. Estimates of the effect of the inheritance shock using Probit models

Table 15 Probit estimates of the effect of inheritance shock on hospitalization (in percent), main sample

Model 1

(1)

\begin{tabular}{lll}
\hline Effect & $2.937 * *$ & $0.150 *$ \\
& $(1.433)$ & $(0.075)$ \\
& {$[0.413]$} & {$[0.021]$} \\
$N$ & 79,801 & 79,801 \\
$N T$ & $1,356,617$ & $1,356,617$ \\
\hline
\end{tabular}

Model 2

(2)

Coefficient estimates are reported in percent. Standard errors (in percent) clustered at individual, in parentheses. Marginal effects (in percent) calculated using delta method in brackets. The models include time, year, and individual fixed effects, in addition to a second-order polynomial in age

*Significant at the $10 \%$ level; **significant at the $5 \%$ level

\section{Appendix 6. Estimates of the effect of inheritance on hospitalization}

Table 16 Difference-in-difference (DID) estimates, impact of inheritance shock on hospitalization (in percent), and Model 1 and Model 2 with controls for inheritance size, main sample

\begin{tabular}{|c|c|c|c|c|c|c|}
\hline & $\begin{array}{l}\text { Model } 1 \\
\text { (1) }\end{array}$ & (2) & (3) & $\begin{array}{l}\text { Model } 2 \\
\text { (4) }\end{array}$ & (5) & (6) \\
\hline Effect & $\begin{array}{l}0.459 * * \\
(0.210)\end{array}$ & $\begin{array}{l}0.459 * * \\
(0.210)\end{array}$ & $\begin{array}{l}0.459 * * \\
(0.210)\end{array}$ & $\begin{array}{l}0.0441 * * \\
(0.0198)\end{array}$ & $\begin{array}{l}0.0403 * * \\
(0.0199)\end{array}$ & $\begin{array}{l}0.0435 * * \\
(0.0201)\end{array}$ \\
\hline Inheritance & $\begin{array}{l}-0.00375 \\
(0.00476)\end{array}$ & $\begin{array}{l}0.012 \\
(0.0087)\end{array}$ & & $\begin{array}{l}-0.00508 \\
(0.0048)\end{array}$ & $\begin{array}{l}0.00921 \\
(0.00879)\end{array}$ & \\
\hline Inheritance $^{2}$ & & $\begin{array}{l}-0.00002 * * * \\
(0.000006)\end{array}$ & & & $\begin{array}{l}-0.0000143 * * \\
(0.0000058)\end{array}$ & \\
\hline Inheritance $^{3}$ & & $\begin{array}{l}1.40 \mathrm{e}-7 * * * \\
(5.17 \mathrm{e}-8)\end{array}$ & & & $\begin{array}{l}1.32 \mathrm{e}-7 * * \\
(5.19 \mathrm{e}-8)\end{array}$ & \\
\hline Inheritance, log & & & $\begin{array}{l}0.00119 \\
(0.06293)\end{array}$ & & & $\begin{array}{l}0.02793 \\
(0.0643)\end{array}$ \\
\hline
\end{tabular}

Coefficient estimates are reported in percent. Standard errors (in percent) clustered at individual, in parentheses. The estimations are based on 1,356,617 observations (17 years $\times 79,801$ heirs). Inheritance refers to inheritance value in 100,000 SEK (2003 prices). The models are estimated with a second-order polynomial in age

$* *$ Significant at the $5 \%$ level; ***significant at the $1 \%$ level 


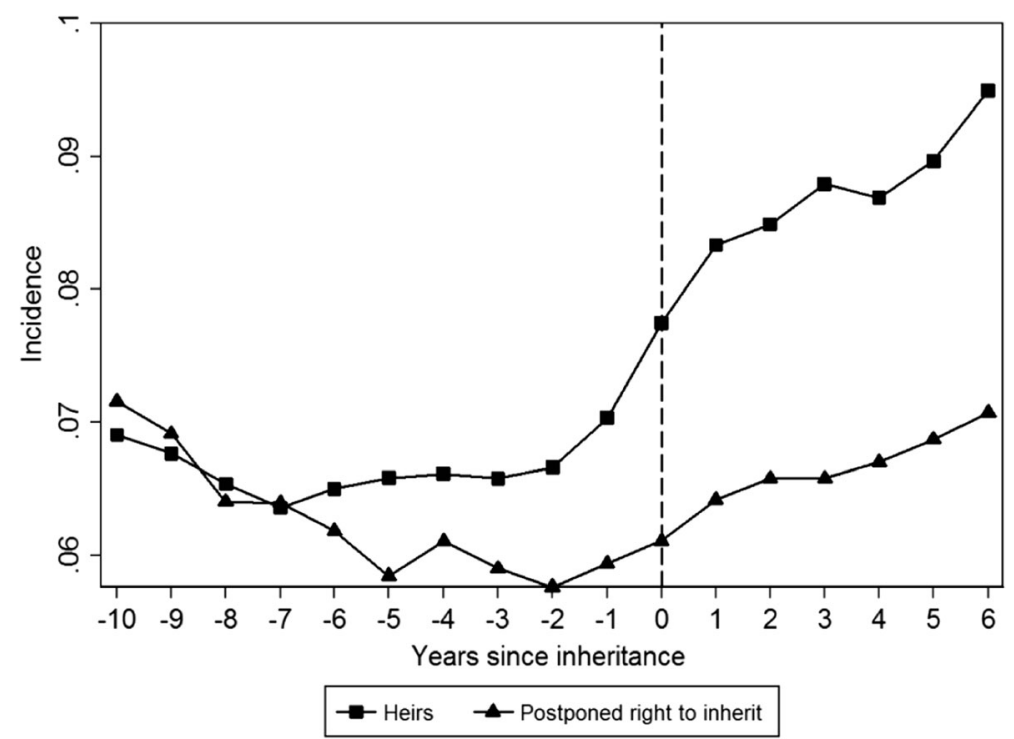

Fig. 3 The annual incidence of hospitalization for heirs and heirs with postponed right to inherit. Note: the vertical line indicates the point in time when the inheritance is received

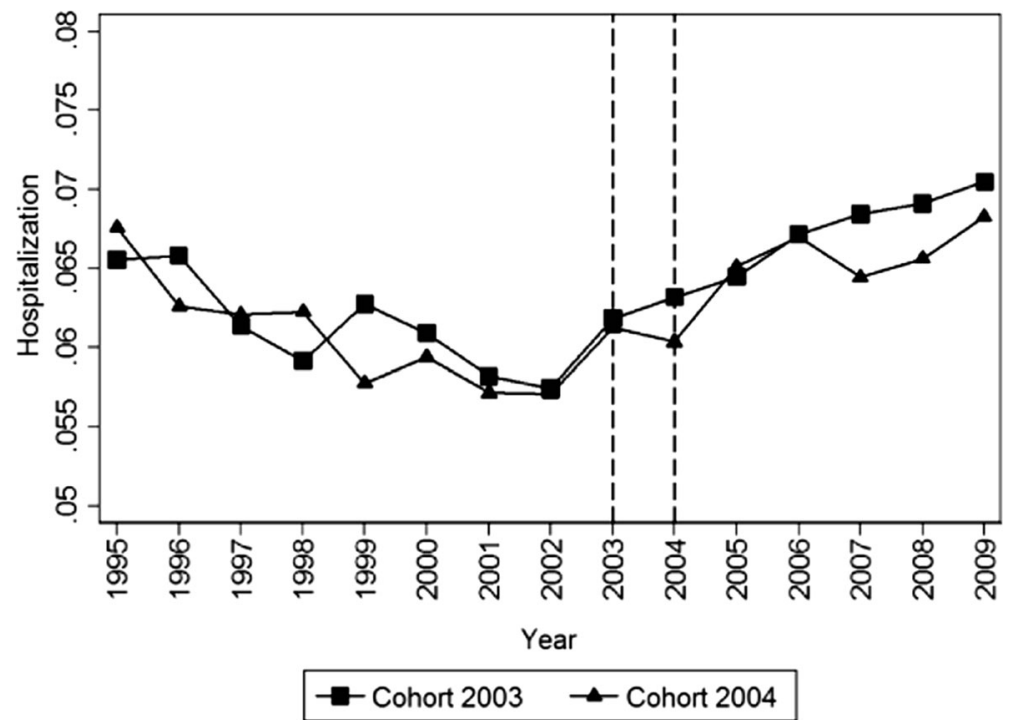

Fig. 4 The annual incidence of hospitalization for heirs of the 2003 cohort and heirs of the 2004 cohort. Note: the vertical lines indicate the calendar year when the inheritance is received 
Table 17 Estimates of the effect of inheritance on hospitalization (in percent)

Strategy 1

(1)

\begin{tabular}{lll}
\hline Effect & $1.634 * * *$ & $2.692 * * *$ \\
& $(0.089)$ & $(0.154)$ \\
Mean of outcome & 6.62 & 7.16 \\
Effect in $\%$ & 24.7 & 37.7 \\
$N$ & 103,798 & 51,964 \\
$N * T$ & $1,764,566$ & 724,496 \\
\hline
\end{tabular}

Coefficient estimates are reported in percent. Standard errors (in percent) clustered at individual, in parentheses. The models include time, year, and individual fixed effects, in addition to a second-order polynomial in age. Effect in \% is calculated as (Effect / Mean of outcome) $\times 100$

$* * *$ Significant at the $1 \%$ level

\section{Appendix 7. Estimates of the effect of the inheritance shock using sudden deaths}

Table 18 Estimates of the effect of inheritance shock on hospitalization (in percent), main sample: sudden deaths

Model 1

(1)

Effect

$0.906 *$

(0.486)

N

14,384

244,528
Model 2

(2)

0.069

14,384

244,528

Coefficient estimates are reported in percent. Standard errors (in percent) clustered at individual, in parentheses. The models include time, year, and individual fixed effects, in addition to a second-order polynomial in age

*Significant at the $10 \%$ level 


\section{Appendix 8. Additional results in Section 7.6}

Table 19 Placebo tests, impact of inheritance shock on hospitalization (in percent), and dynamics of responses, Model 1

\section{Placebo test}

I

(1)

DID estimate by year since inheritance

\begin{tabular}{|c|c|c|c|}
\hline \multirow[t]{2}{*}{-8} & $0.690 * * *$ & 0.357 & 0.648 \\
\hline & $(0.257)$ & $(0.319)$ & $(0.817)$ \\
\hline \multirow[t]{2}{*}{-7} & 0.229 & -0.292 & -0.579 \\
\hline & $(0.291)$ & $(0.350)$ & $(0.822)$ \\
\hline \multirow[t]{2}{*}{-6} & 0.442 & -0.215 & -0.601 \\
\hline & $(0.298)$ & $(0.356)$ & $(0.826)$ \\
\hline \multirow[t]{2}{*}{-5} & 0.217 & 0.327 & 0.386 \\
\hline & $(0.303)$ & $(0.361)$ & $(0.845)$ \\
\hline \multirow[t]{2}{*}{-4} & 0.258 & 0.201 & 0.369 \\
\hline & $(0.306)$ & $(0.364)$ & $(0.865)$ \\
\hline \multirow[t]{2}{*}{-3} & 0.324 & 0.433 & 0.508 \\
\hline & $(0.307)$ & $(0.365)$ & $(0.854)$ \\
\hline \multirow[t]{2}{*}{-2} & 0.159 & 0.0539 & -0.194 \\
\hline & $(0.313)$ & $(0.372)$ & $(0.875)$ \\
\hline \multirow[t]{2}{*}{-1} & -0.0973 & 0.0967 & 0.987 \\
\hline & $(0.317)$ & $(0.376)$ & $(0.908)$ \\
\hline \multirow[t]{2}{*}{0} & 0.144 & -0.0848 & -0.520 \\
\hline & $(0.328)$ & $(0.377)$ & $(0.874)$ \\
\hline \multirow[t]{2}{*}{1} & 0.409 & -0.418 & 1.180 \\
\hline & $(0.334)$ & $(0.381)$ & $(0.983)$ \\
\hline \multirow[t]{2}{*}{2} & 0.288 & -0.156 & 0.970 \\
\hline & $(0.337)$ & $(0.385)$ & (1.010) \\
\hline \multirow[t]{2}{*}{3} & 0.249 & 0.444 & 1.060 \\
\hline & $(0.338)$ & $(0.387)$ & $(0.987)$ \\
\hline \multirow[t]{2}{*}{4} & 0.0006 & 0.103 & 1.250 \\
\hline & $(0.343)$ & $(0.388)$ & (0.977) \\
\hline \multirow[t]{2}{*}{5} & 0.335 & -0.0141 & 0.603 \\
\hline & $(0.349)$ & $(0.393)$ & $(0.981)$ \\
\hline \multirow[t]{2}{*}{6} & 0.00454 & -0.0109 & 0.634 \\
\hline & $(0.719)$ & $(0.804)$ & (1.010) \\
\hline$N$ & 134,172 & 77,309 & 51,964 \\
\hline$N * T$ & $2,280,924$ & $1,314,253$ & 883,388 \\
\hline
\end{tabular}

Coefficient estimates are reported in percent. Standard errors (in percent) clustered at individual, in parentheses. The model specifications include year, time, and individual fixed effects, in addition to a second-order polynomial in age

***Significant at the $1 \%$ level
III

(3)
$0.817)$

0.579

$(0.822)$

$0.826)$

0.386

$(0.845)$

0.508

$(0.854)$

$-0.194$

0.875

0.987

0.520

$0.874)$

1.180

$0.983)$

.970

1.060

$(0.987)$

1.250

$0.977)$

$0.981)$

0.634

1.010)

51,964

83,388 


\section{Appendix 9. DID estimates and heterogeneous effects, hospitalization}

Table 20 Difference-in-difference (DID) estimates, impact of inheritance shock on hospitalization (in percent), and heterogeneous effects with respect to demographic characteristics, Model 1 and Model 2, main sample

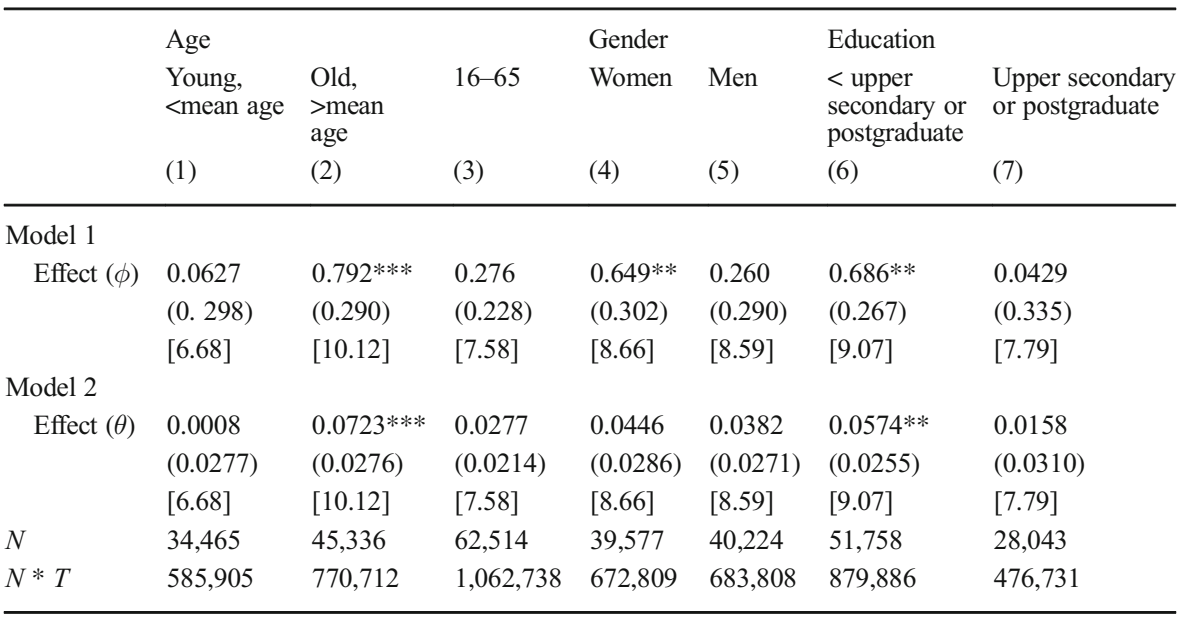

Coefficient estimates are reported in percent. Standard errors (in percent) clustered at individual, in parentheses. Mean of dependent variable (in percent), post-inheritance period for control group, in brackets. The model specifications include year, time, and individual fixed effects, in addition to a second-order polynomial in age

**Significant at the $5 \%$ level; ***significant at the $1 \%$ level

Table 21 Difference-in-difference (DID) estimates, impact of inheritance shock on hospitalization (in percent), and heterogeneous effects with respect to inheritance shock, per quartile of the distribution, Model 1 and Model 2, main sample

\begin{tabular}{|c|c|c|c|c|c|c|c|c|}
\hline & \multicolumn{4}{|c|}{$\begin{array}{l}\text { Inheritance shock, by quartile of the } \\
\text { distribution }\end{array}$} & \multicolumn{4}{|c|}{$\begin{array}{l}\text { Inheritance shock/initial (gross) wealth, by quar- } \\
\text { tile of the distribution }\end{array}$} \\
\hline & $\begin{array}{l}1 \mathrm{st} \\
\text { (1) }\end{array}$ & $\begin{array}{l}\text { 2nd } \\
\text { (2) }\end{array}$ & $\begin{array}{l}\text { 3rd } \\
\text { (3) }\end{array}$ & $\begin{array}{l}\text { 4th } \\
\text { (4) }\end{array}$ & $\begin{array}{l}1 \mathrm{st} \\
\text { (5) }\end{array}$ & $\begin{array}{l}\text { 2nd } \\
\text { (6) }\end{array}$ & $\begin{array}{l}3 r d \\
\text { (7) }\end{array}$ & $\begin{array}{l}\text { 4th } \\
\text { (8) }\end{array}$ \\
\hline \multicolumn{9}{|l|}{ Model 1} \\
\hline Effect $(\phi)$ & $\begin{array}{l}0.536 \\
(0.423) \\
{[9.14]}\end{array}$ & $\begin{array}{l}0.0748 \\
(0.427) \\
{[8.81]}\end{array}$ & $\begin{array}{l}0.846 * * \\
(0.420) \\
{[8.48]}\end{array}$ & $\begin{array}{l}0.401 \\
(0.406) \\
{[8.07]}\end{array}$ & $\begin{array}{l}0.295 \\
(0.414) \\
{[8.53]}\end{array}$ & $\begin{array}{l}0.409 \\
(0.405) \\
{[8.10]}\end{array}$ & $\begin{array}{l}0.820 * \\
(0.421) \\
{[8.55]}\end{array}$ & $\begin{array}{l}0.342 \\
(0.435) \\
{[9.31]}\end{array}$ \\
\hline \multicolumn{9}{|l|}{ Model 2} \\
\hline Effect $(\theta)$ & $\begin{array}{l}0.0345 \\
(0.0519) \\
{[9.14]}\end{array}$ & $\begin{array}{l}0.0008 \\
(0.0451) \\
{[8.81]}\end{array}$ & $\begin{array}{l}0.0793 * * \\
(0.0404) \\
{[8.48]}\end{array}$ & $\begin{array}{l}0.0370 \\
(0.0337) \\
{[8.07]}\end{array}$ & $\begin{array}{l}0.040 \\
(0.043) \\
{[8.53]}\end{array}$ & $\begin{array}{l}0.016 \\
(0.039) \\
{[8.10]}\end{array}$ & $\begin{array}{l}0.072 * \\
(0.038) \\
{[8.55]}\end{array}$ & $\begin{array}{l}0.034 \\
(0.039) \\
{[9.31]}\end{array}$ \\
\hline$N$ & 19,949 & 19,950 & 19,951 & 19,951 & 19,950 & 19,950 & 19,950 & 19,951 \\
\hline$N * T$ & 339,133 & 339,150 & 339,167 & 339,167 & 339,150 & 339,150 & 339,150 & 339,167 \\
\hline
\end{tabular}

Coefficient estimates are reported in percent. Standard errors (in percent) clustered at individual, in parentheses. Mean of dependent variable (in percent), post-inheritance period for control group, in brackets. The model specifications include year, time, and individual fixed effects, in addition to a second-order polynomial in age *Significant at the $10 \%$ level; **significant at the $5 \%$ level 


\section{Appendix 10. Additional results for Section 7.8}

Table 22 Difference-in-difference (DID) estimates and impact of inheritance shock on diagnosis categories (in percent), main sample

Model 1

(1)

\section{Outcome}

Neoplasms

$0.157 * *$

(0.0755)

[1.13]

Mental

$-0.0844$

(0.0656)

[0.64]

Nervous

Circulatory

Respiratory

$-0.0174$

(0.0457)

[0.40]

0.0771

(0.0857)

[1.55]

0.0254

(0.0478)

[0.48]

Digestive

Musculoskeletal

0.0220

(0.0723)

[0.98]

0.0009

(0.0662)

[0.88]

Genitourinary

Symptoms and signs

0.0237

(0.0574)

[0.61]

0. $177^{* *} *$

(0.0741)

[1.09]

Injury

0.0444

(0.0691)

[0.10]

Others

$N$

0.0363

(0.0836)

[1.46]

79,801

$1,356,617$
Model 2

(2)

$0.0156^{* *}$

(0.0007)

[1.13]

$-0.0007$

(0.0006)

[0.64]

$-0.0001$

(0.0004)

[0.40]

0.0007

(0.0008)

[1.55]

$-0.0001$

(0.0005)

[0.48]

$-0.00003$

(0.0007)

[0.98]

$-0.00004$

(0.0006)

[0.88]

0.0003

(0.0005)

[0.61]

$0.0157^{* *}$

(0.0007)

[1.09]

0.0009

(0.0006)

[0.10]

0.00008

(0.0008)

[1.46]

79,801

$1,356,617$

Coefficient estimates are reported in percent. Standard errors (in percent) clustered at individual, in parentheses. Mean of dependent variable (in percent), post-inheritance period for control group, in brackets. The model specifications include year, time, and individual fixed effects, in addition to a second-order polynomial in age ** Significant at the $10 \%$ level 
Table 23 Placebo tests and impact of inheritance shock on hospitalization (in percent), Model 1

\begin{tabular}{|c|c|c|c|c|c|c|}
\hline \multirow[b]{3}{*}{ Outcome } & \multicolumn{6}{|l|}{ Placebo test } \\
\hline & \multicolumn{2}{|l|}{ I } & \multicolumn{2}{|l|}{ II } & \multicolumn{2}{|l|}{ III } \\
\hline & $\begin{array}{l}\text { Symptoms and signs } \\
\text { (1) }\end{array}$ & $\begin{array}{l}\text { Neoplasms } \\
\text { (2) }\end{array}$ & $\begin{array}{l}\text { Symptoms and signs } \\
\text { (3) }\end{array}$ & $\begin{array}{l}\text { Neoplasms } \\
\text { (4) }\end{array}$ & $\begin{array}{l}\text { Symptoms and signs } \\
\text { (5) }\end{array}$ & $\begin{array}{l}\text { Neoplasms } \\
\text { (6) }\end{array}$ \\
\hline Effect $(\phi)$ & $\begin{array}{l}0.093 \\
(0.066)\end{array}$ & $\begin{array}{l}0.001 \\
(0.061)\end{array}$ & $\begin{array}{l}0.021 \\
(0.065)\end{array}$ & $\begin{array}{l}-0.086 \\
(0.059)\end{array}$ & $\begin{array}{l}-0.064 \\
(0.047)\end{array}$ & $\begin{array}{l}-0.034 \\
(0.049)\end{array}$ \\
\hline$N$ & 134,172 & 134,172 & 77,309 & 77,309 & 51,964 & 51,964 \\
\hline$N * T$ & $2,280,924$ & $2,280,924$ & $1,314,253$ & $1,314,253$ & 883,388 & 883,388 \\
\hline
\end{tabular}

Coefficient estimates are reported in percent. Standard errors (in percent) clustered at individual, in parentheses. The models include time, year and individual fixed effects, in addition to a second order polynomial in age

Table 24 Difference-in-difference (DID) estimates, impact of wealth shock on symptoms and signs and neoplasms (in percent), dynamics of responses, Model 1 and Model 2, main sample

\begin{tabular}{|c|c|c|c|c|}
\hline \multirow[b]{2}{*}{ Outcome } & \multicolumn{2}{|l|}{ Model 1} & \multicolumn{2}{|l|}{ Model 2} \\
\hline & $\begin{array}{l}\text { Symptoms and signs } \\
\text { (1) }\end{array}$ & $\begin{array}{l}\text { Neoplasm } \\
\text { (2) }\end{array}$ & $\begin{array}{l}\text { Symptoms and signs } \\
\text { (3) }\end{array}$ & $\begin{array}{l}\text { Neoplasm } \\
\text { (4) }\end{array}$ \\
\hline \multicolumn{5}{|c|}{ DID estimate by year since inheritance } \\
\hline-8 & $\begin{array}{l}-0.0113 \\
(0.120)\end{array}$ & $\begin{array}{l}-0.102 \\
(0.0887)\end{array}$ & $\begin{array}{l}-0.0003 \\
(0.0113)\end{array}$ & $\begin{array}{l}-0.001 \\
(0.001)\end{array}$ \\
\hline-7 & $\begin{array}{l}0.182 \\
(0.134)\end{array}$ & $\begin{array}{l}-0.001 \\
(0.102)\end{array}$ & $\begin{array}{l}0.0144 \\
(0.0127)\end{array}$ & $\begin{array}{l}0.0003 \\
(0.001)\end{array}$ \\
\hline-6 & $\begin{array}{l}-0.0372 \\
(0.136)\end{array}$ & $\begin{array}{l}0.0174 \\
(0.109)\end{array}$ & $\begin{array}{l}-0.0001 \\
(0.0128)\end{array}$ & $\begin{array}{l}0.001 \\
(0.0103)\end{array}$ \\
\hline-5 & $\begin{array}{l}-0.112 \\
(0.137)\end{array}$ & $\begin{array}{l}0.0406 \\
(0.111)\end{array}$ & $\begin{array}{l}-0.001 \\
(0.0130)\end{array}$ & $\begin{array}{l}0.0003 \\
(0.0105)\end{array}$ \\
\hline-4 & $\begin{array}{l}0.001 \\
(0.137)\end{array}$ & $\begin{array}{l}0.0624 \\
(0.114)\end{array}$ & $\begin{array}{l}0.0002 \\
(0.0129)\end{array}$ & $\begin{array}{l}0.0003 \\
(0.0106)\end{array}$ \\
\hline-3 & $\begin{array}{l}0.0445 \\
(0.137)\end{array}$ & $\begin{array}{l}-0.0311 \\
(0.113)\end{array}$ & $\begin{array}{l}-0.0001 \\
(0.0128)\end{array}$ & $\begin{array}{l}-0.0001 \\
(0.0106)\end{array}$ \\
\hline-2 & $\begin{array}{l}0.0916 \\
(0.141)\end{array}$ & $\begin{array}{l}0.0563 \\
(0.117)\end{array}$ & $\begin{array}{l}0.001 \\
(0.0133)\end{array}$ & $\begin{array}{l}0.001 \\
(0.0110)\end{array}$ \\
\hline-1 & $\begin{array}{l}0.248^{*} \\
(0.144)\end{array}$ & $\begin{array}{l}-0.097 \\
(0.126)\end{array}$ & $\begin{array}{l}0.0213 \\
(0.0136)\end{array}$ & $\begin{array}{l}-0.0002 \\
(0.0119)\end{array}$ \\
\hline 0 & $\begin{array}{l}0.246^{*} \\
(0.147)\end{array}$ & $\begin{array}{l}-0.0674 \\
(0.140)\end{array}$ & $\begin{array}{l}0.0213 \\
(0.0138)\end{array}$ & $\begin{array}{l}-0.0002 \\
(0.0133)\end{array}$ \\
\hline 1 & $\begin{array}{l}0.0923 \\
(0.153)\end{array}$ & $\begin{array}{l}-0.0685 \\
(0.143)\end{array}$ & $\begin{array}{l}0.001 \\
(0.0144)\end{array}$ & $\begin{array}{l}-0.0004 \\
(0.0135)\end{array}$ \\
\hline 2 & $\begin{array}{l}0.318^{* *} \\
(0.152)\end{array}$ & $\begin{array}{l}0.331 * * \\
(0.144)\end{array}$ & $\begin{array}{l}0.0310 * * \\
(0.0143)\end{array}$ & $\begin{array}{l}0.0356 * * * \\
(0.0137)\end{array}$ \\
\hline 3 & $\begin{array}{l}0.264 * \\
(0.151)\end{array}$ & $\begin{array}{l}0.322 * * \\
(0.144)\end{array}$ & $\begin{array}{l}0.0257 * \\
(0.0142)\end{array}$ & $\begin{array}{l}0.0347 * * \\
(0.0137)\end{array}$ \\
\hline 4 & $\begin{array}{l}0.234 \\
(0.152)\end{array}$ & $\begin{array}{l}0.314 * * \\
(0.151)\end{array}$ & $\begin{array}{l}0.0275^{*} \\
(0.0145)\end{array}$ & $\begin{array}{l}0.0309^{* *} \\
(0.0143)\end{array}$ \\
\hline 5 & 0.211 & 0.104 & 0.0165 & 0.0104 \\
\hline
\end{tabular}


Table 24 (continued)

\begin{tabular}{|c|c|c|c|c|}
\hline \multirow[b]{2}{*}{ Outcome } & \multicolumn{2}{|l|}{ Model 1} & \multicolumn{2}{|l|}{ Model 2} \\
\hline & $\begin{array}{l}\text { Symptoms and signs } \\
\text { (1) }\end{array}$ & $\begin{array}{l}\text { Neoplasm } \\
\text { (2) }\end{array}$ & $\begin{array}{l}\text { Symptoms and signs } \\
\text { (3) }\end{array}$ & $\begin{array}{l}\text { Neoplasm } \\
\text { (4) }\end{array}$ \\
\hline \multirow{3}{*}{6} & $(0.156)$ & $(0.157)$ & $(0.0147)$ & $(0.0149)$ \\
\hline & 0.303 & 0.243 & -0.001 & 0.0119 \\
\hline & $(0.374)$ & $(0.373)$ & $(0.0288)$ & $(0.0272)$ \\
\hline$N$ & 79,801 & 79,801 & 79,801 & 79,801 \\
\hline$N * T$ & $1,356,617$ & $1,356,617$ & $1,356,617$ & $1,356,617$ \\
\hline
\end{tabular}

Coefficient estimates are reported in percent. Standard errors (in percent) clustered at individual, in parentheses. The model specifications include year, time, and individual fixed effects, in addition to a second-order polynomial in age

*Significant at the $10 \%$ level; **significant at the $5 \%$ level; ***significant at the $1 \%$ level

Table 25 Difference-in-difference (DID) estimates, impact of wealth shock on symptoms and signs (in percent), and dynamics of responses, Model 1 and Model 2, main sample: sudden deaths

Model 1

(1)

DID estimate by year since inheritance

$-8$

$-7$

$-6$

$-5$

$-4$

$-3$

$-2$

$-1$

0

1

2

3
Model 2

(2)

$-0.0148$

(0.0260)

0.0211

(0.0295)

$-0.0092$

(0.0298)

0.0202

$(0.0314)$

0.0496

(0.0310)

0.0073

(0.0308)

$-0.0121$

(0.0308)

0.0119

(0.0318)

$-0.0053$

(0.0327)

0.0290

(0.0325)

0.0837 **

(0.0355)

0.0236

(0.0320) 
Table 25 (continued)

Model 1

(1)

\begin{tabular}{cll}
\hline 4 & 0.260 & 0.0267 \\
5 & $(0.347)$ & $(0.0341)$ \\
& 0.598 & 0.0384 \\
6 & $(0.369)$ & $(0.0345)$ \\
& 0.525 & 0.0494 \\
$N$ & $(0.738)$ & $(0.0667)$ \\
$N * T$ & 14,384 & 14,384 \\
\hline
\end{tabular}

Coefficient estimates are reported in percent. Standard errors (in percent) clustered at individual, in parentheses. The model specifications include year, time, and individual fixed effects, in addition to a second-order polynomial in age

**Significant at the $5 \%$ level

\section{Appendix 11. DID estimates of the effect of the inheritance shock on sick leave and mortality}

Table 26 Difference-in-difference (DID) estimates and impact of inheritance shock on sick leave (in percent), Model 1 and Model 2, main sample

(1)

(2)

(3)

(4)

Model 1

Effect $(\phi)$

$-1.12 * * *$
$(0.201)$
$[8.63]$

0.311

0.274

0.184

$0.386)$

(0.382)

[8.63]

(0.378)

[8.63]

[8.63]

Model 2

Effect $(\theta)$

$$
-0.112 * * *
$$

0.0274

0.0250

0.0260

(0.0196)

(0.0353)

(0.0352)

[8.63]

[8.63]

[8.63]

[8.63]

Year FE

No

Yes

Yes

Yes

Covariates

No

No

Yes

Yes

Individual FE

No

No

No

Yes

N $\quad 61,584$

$N * T$

911,750

61,584

61,584

911,750

911,750

911,750

Coefficient estimates are reported in percent. Standard errors (in percent) clustered at individual, in parentheses. Mean of dependent variable (in percent), post-inheritance period for control group, in brackets. Covariates in columns 3 and 7 include gender, a second order polynomial in age, marital status, presence of children, level of education, income, wealth, and baseline health, whereas covariates in columns 4 and 8 include a second order polynomial in age

$* * *$ Significant at the $1 \%$ level 
Table 27 Difference estimates and difference-in-difference (DID) estimates, and impact of inheritance shock on mortality (in percent)

\begin{tabular}{|c|c|c|c|}
\hline & $\begin{array}{l}\text { Differences es } \\
\text { Main sample } \\
\text { (1) }\end{array}$ & $\begin{array}{l}\text { BTT sample } \\
\text { (2) }\end{array}$ & $\begin{array}{l}\text { DID estimates } \\
1-2 \\
\text { (3) }\end{array}$ \\
\hline \multicolumn{4}{|l|}{ Outcome } \\
\hline Mortality1 & $\begin{array}{l}-0.06 \\
(0.08) \\
{[0.78]}\end{array}$ & $\begin{array}{l}-0.01 \\
(0.06) \\
{[0.92]}\end{array}$ & $\begin{array}{l}-0.06 \\
(0.10)\end{array}$ \\
\hline Mortality2 & $\begin{array}{l}-0.05 \\
(0.10) \\
{[1.33]}\end{array}$ & $\begin{array}{l}0.06 \\
(0.08) \\
{[1.50]}\end{array}$ & $\begin{array}{l}-0.11 \\
(0.13)\end{array}$ \\
\hline Mortality3 & $\begin{array}{l}-0.06 \\
(0.12) \\
{[1.85]}\end{array}$ & $\begin{array}{l}0.10 \\
(0.10) \\
{[2.16]}\end{array}$ & $\begin{array}{l}-0.16 \\
(0.15)\end{array}$ \\
\hline Mortality4 & $\begin{array}{l}-0.06 \\
(0.13) \\
{[2.39]}\end{array}$ & $\begin{array}{l}0.08 \\
(0.11) \\
{[2.84]}\end{array}$ & $\begin{array}{l}-0.14 \\
(0.17)\end{array}$ \\
\hline Mortality 5 & $\begin{array}{l}-0.10 \\
(0.15) \\
{[3.04]}\end{array}$ & $\begin{array}{l}0.13 \\
(0.13) \\
{[3.62]}\end{array}$ & $\begin{array}{l}-0.23 \\
(0.20)\end{array}$ \\
\hline Mortality6 & $\begin{array}{l}-0.06 \\
(0.16) \\
{[3.66]}\end{array}$ & $\begin{array}{l}0.04 \\
(0.14) \\
{[4.49]}\end{array}$ & $\begin{array}{l}-0.10 \\
(0.21)\end{array}$ \\
\hline$N$ & 51,835 & 86,733 & 138,568 \\
\hline
\end{tabular}

Coefficient estimates are reported in percent. Robust standard errors (in percent) in parentheses. Mean of dependent variable (in percent), for control group in brackets. The estimates have been obtained from models with controls for age, age ${ }^{2}$, gender, marital status, presence of children, level of education (highest achieved), earned income, and net worth, measured 3 years before the inheritance 
Appendix 12. Estimates of the effect of parental death on hospitalization and sick leave

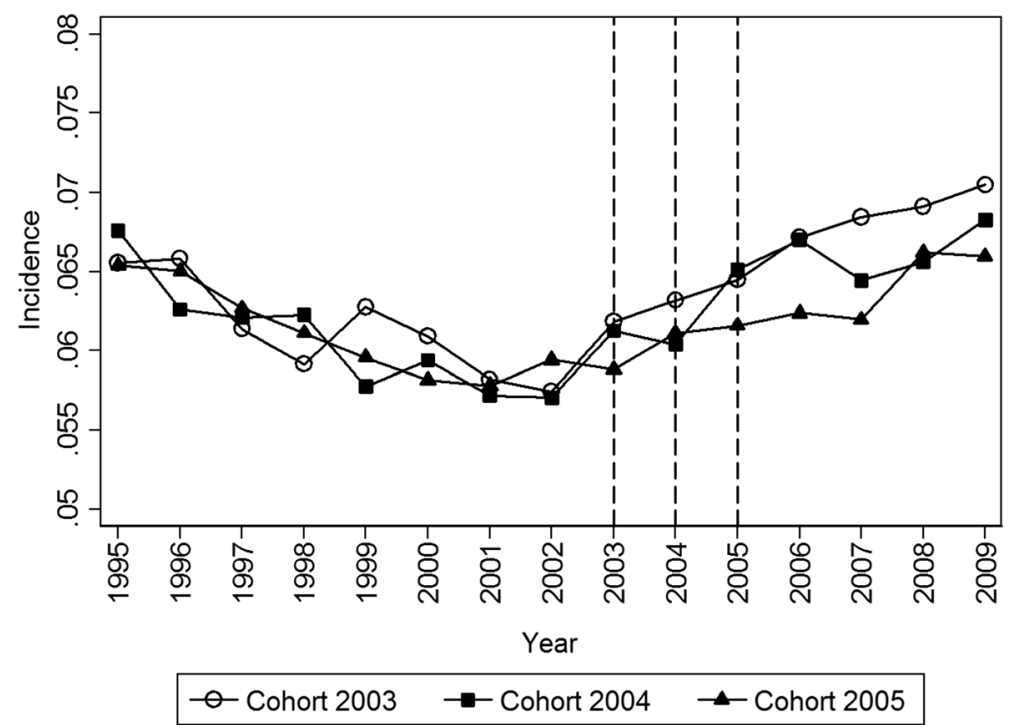

Fig. 5 The annual incidence of hospitalization for heirs with postponed right to inherit, by cohort. Note: the vertical lines indicate the year when the inheritance is received

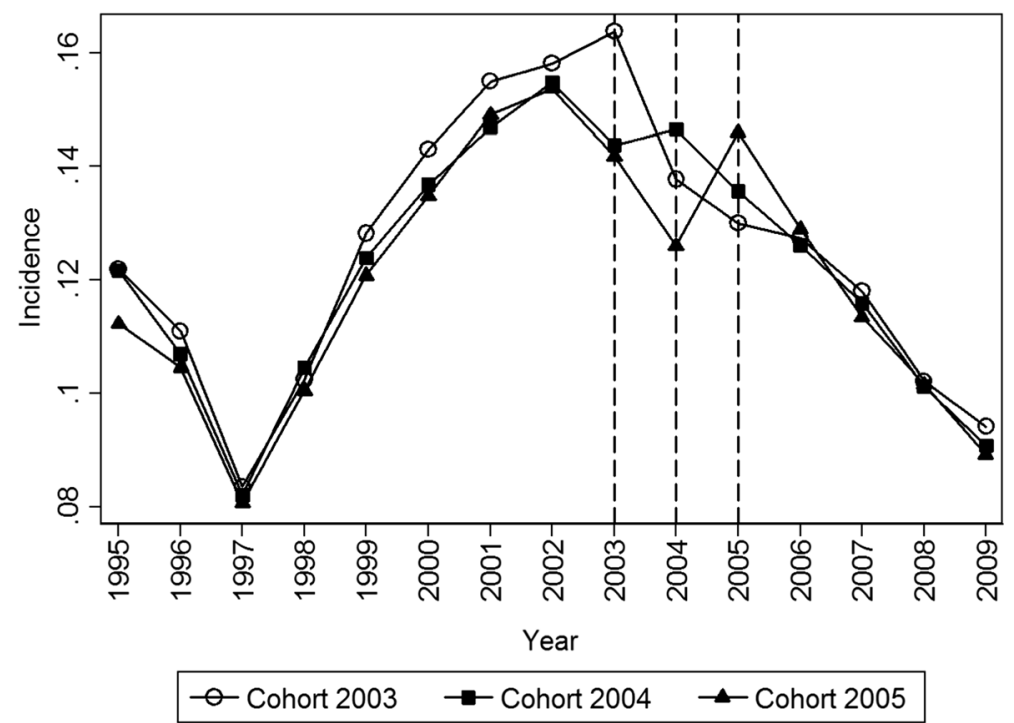

Fig. 6 The annual incidence of sick leave for heirs with postponed right to inherit, by cohort. Note: the vertical lines indicate the year when the inheritance is received 
Table 28 Estimates of the effect of parental loss on hospitalization and sick leave (in percent)

\begin{tabular}{lll}
\hline & $\begin{array}{l}\text { Hospitalization } \\
(1)\end{array}$ & $\begin{array}{l}\text { Sick leave } \\
(2)\end{array}$ \\
\hline Effect & 0.034 & $0.791 * * *$ \\
& $(0.213)$ & $(0.285)$ \\
Mean of outcome & 6.00 & 14.25 \\
Effect in \% & 0.5 & 5.5 \\
$N$ & 77,309 & 74,615 \\
$N * T$ & $1,082,326$ & 945,147 \\
\hline
\end{tabular}

Coefficient estimates are reported in percent. Standard errors (in percent) clustered at individual, in parentheses. The models include time, year, and individual fixed effects, in addition to a second-order polynomial in age. Effect in \% is calculated as (Effect / Mean of outcome) $\times 100$

$* * *$ Significant at the $1 \%$ level

Open Access This article is distributed under the terms of the Creative Commons Attribution 4.0 International License (http://creativecommons.org/licenses/by/4.0/), which permits unrestricted use, distribution, and reproduction in any medium, provided you give appropriate credit to the original author(s) and the source, provide a link to the Creative Commons license, and indicate if changes were made.

\section{References}

Adams P, Hurd MD, Mcfadden D, Merrill A, Ribeiro T (2003) Healthy, wealthy, and wise? Tests for direct causal paths between health and socioeconomic status. J Econ 112:3-56

Adda J, Banks J, von Gaudecker H-M (2009) The impact of income shocks on health: evidence from cohort data. J Eur Econ Assoc 7:1361-1399

Almond D, Currie J (2013) Killing me softly: the fetal origins hypothesis. J Econ Perspect 25:153-172

Andersen S, Nielsen KM (2011) Participation constraints in the stock market: evidence from unexpected inheritance due to sudden death. Rev Financ Stud 24:1667-1697

Apouey B, Clark AE (2015) Winning big but feeling no better? The effect of lottery prizes on physical and mental health. Health Econ 24:516-538

Bago d'Uva T, van Doorslaer E, Lindeboom M, O’Donnell O, Chatterji S (2008) Does reporting heterogeneity bias the measurement of health disparities? Health Econ 17:351-375

Barker DJ (1997) Maternal nutrition, fetal nutrition and diseases later in life. Nutrition 13:807-813

Barsky RB, Juster FT, Kimball MS, Shapiro MD (1997) Preference parameters and behavioral heterogeneity: an experimental approach in the health and retirement study. Q J Econ 112:537-579

Becker GS (1976) The economic approach to human behavior. University of Chicago Press, Chicago

Benzeval M, Judge K (2001) Income and health: the time dimension. Soc Sci Med 52:1371-1390

Bø, E. E., Halvorsen, E., and T. O. Thoresen (2016). Heterogeneity of the Carnegie effect, Statistics Norway Discussion Paper No. 853

Briggs, J., D. Cesarini, E. Lindqvist and R. Östling (2015) Windfall gains and stock market participation, NBER Working Paper No. 21673

Brown JR, Coile CC, Weisbenner SJ (2010) The effect of inheritance receipt on retirement. Rev Econ Stat 92: 425-434

Carman KG (2013) Inheritances, intergenerational transfers, and the accumulation of health. Am Econ Rev Pap Proc 103:451-455

Case A (2004) Does money protect health status? Evidence from South African pensions. In: Wise D (ed) Perspectives on the economics of aging. University of Chicago Press, Chicago

Case A, Paxson C (2005) Sex differences in morbidity and mortality. Demography 42:189-212 
Cawley J, Ruhm CJ (2011) The economics of risky health behaviors. In: Mark TGM, Pauly V, Pedro PB (eds) Handbook of health economics. Elsevier, Amsterdam

Cesarini, D., E. Lindqvist, M. J. Notowidigdo and R. Östling (2015). The effect of wealth on individual and household labor supply: evidence from Swedish lotteries, NBER Working Paper No. 21762

Cesarini D, Lindqvist E, Östling R, Wallace B (2016) Wealth, health, and child development: evidence from administrative data on Swedish lottery players. Q J Econ 131:687-738

Chida Y, Steptoe A (2008) Positive psychological wellbeing and mortality: a quantitative review of prospective observational studies. Psychosom Med 70:741-756

Contoyannis P, Jones AM (2004) Socio-economic status, health and lifestyle. J Health Econ 23:965-995

Currie J (2009) Healthy, wealthy, and wise? Socioeconomic status, poor health in childhood, and human capital development. J Econ Lit 47:87-122

Cutler DM, Lleras-Muney A (2010) Understanding differences in health behaviors by education. J Health Econ 29:1-28

Cutler DM, Deaton A, Lleras-Muney A (2011) Socioeconomic status and health: dimensions and mechanisms. In: Glied S, Smith PC (eds) The Oxford handbook of health economics. Oxford University Press, Oxford

Deaton A (2003) Health, inequality, and economic development. J Econ Lit 41:113-158

van Doorslaer E, Gertham U-G (2003) Does inequality in self-assessed health predict inequality in survival by income? Evidence from Swedish data. Soc Sci Med 57:1621-1629

Dufflo E (2000) Child health and household resources: evidence from the South African old-age pension program. Am Econ Rev Pap Proc 90:393-398

Ehrlich I, Chuma H (1990) A model of the demand for longevity and the value of life extension. J Polit Econ 98:761-782

Eliason M, Ohlsson H (2013) Timing of death and the repeal of the Swedish inheritance tax. J Socio-Econ 45: $113-123$

Elinder M, Erixson O, Ohlsson H (2012) The impact of inheritances on heirs' labor and capital income. BE J Econ Anal Policy (Contributions) 12(1):61

Elinder M, Erixson O, Escobar S, Ohlsson H (2014) Estates, bequests, and inheritances in Sweden: a look into the Belinda databases. UCFS Work Pap 2014:14

Elinder, M., O. Erixson, and D. Waldenström (2016) Inheritance and wealth inequality: evidence from population registers CEPR Discussion Paper 11191

Erixson, O. and H. Ohlsson (2014). Estate division: equal sharing as choice, social norm, and legal requirement, Working Paper No 2014:1, Department of Economics, Uppsala University, Uppsala.

Ettner SL (1996) New evidence on the relationship between income and health. J Health Econ 15:67-85

Frijters P, Haisken-DeNew JP, Shields MA (2005) The causal effect of income on health: evidence from German reunification. J Health Econ 24:997-1017

Fuchs VR (1982) Time preferences and health: an exploratory study on economic aspects of health. University of Chicago Press, Chicago

Galama, T. and H. van Kippersluis (2010). A theory of socioeconomic disparities in health over the life cycle, Rand Working Paper, WR-773

Gardner J, Oswald AJ (2007) Money and mental wellbeing: a longitudinal study of medium-sized lottery wins. J Health Econ 26:49-60

Gelman A, Carlin J (2014) Beyond power calculations: assessing type S (sign) and type M (magnitude) errors. Perspect Psychol Sci 9:641-651

Gerdtham UG, Johannesson M (2005) Business cycles and mortality: results from Swedish microdata. Soc Sci Med 60:205-218

Glenngård AH, Hjalte F, Svensson M, Anell A, Bankauskaite V (2005) Health systems in transition: Sweden. WHO Regional Office for Europe on behalf of the European Observatory on Health Systems and Policies, Copenhagen

Goldman DP, Smith JP (2002) Can patient self-management help explain the SES health gradient? Proc Natl Acad Sci USA 99:10929-10934

Grossman M (1972) On the concept of health capital and the demand for health. J Polit Econ 80:223-255

Grossman M (2000) The human capital model. In: Culyer AJ, Newhouse JP (eds) Handbook of health economics. Elsevier, Amsterdam

Henrekson, M. and D. Waldenström (in press) Inheritance taxation in Sweden, 1885-2004: the role of ideology, family firms and tax avoidance, Economic History Review

Hesselius P, Johansson P, Vikström J (2013) Monitoring and norms in sickness insurance: empirical evidence from a natural experiment. Scand J Econ 115:995-1019 
Holtz-Eakin D, Joulfaian D, Rosen HS (1993) The Carnegie conjecture: some empirical evidence. Q J Econ 108:413-435

Idler EL, Benyamini Y (1997) Self-rated health and mortality: a review of twenty-seven community studies. J Health Soc Behav 38:21-37

Imbens G, Rubin D, Sacerdote B (2001) Estimating the effect of unearned income on labor earnings, savings, and consumption: evidence from a survey of lottery players. Am Econ Rev 91:778-794

Jensen RT, Richter K (2004) The health implications of social security failure: evidence from the Russian pension crisis. J Public Econ 88:209-236

Joulfaian D (2004) Gift taxes and lifetime transfers: time series evidence. J Public Econ 88:1917-1929

Kessler R (1997) The effects of stressful life events on depression. Annu Rev Psychol 48:191-214

Kim B, Ruhm CJ (2012) Inheritances, health and death. Health Econ 21:127-144

van Kippersluis H, Galama T (2014) Wealth and health behavior: testing the concept of a health cost. Eur Econ Rev 72:197-220

Kivimäki M, Head J, Ferrie JE, Shipley M, Vahtera J, Marmot MG (2003) Sickness absence as a global measure of health: evidence from mortality in the Whitehall II prospective cohort study. Br Med J 327 : 364-368

Kopczuk W (2007) Bequest and tax planning: evidence from estate tax returns. Q J Econ 122:1801-1854

Kopczuk, W. and J. Slemrod. (2005). Denial of death and economic behavior, Advances in Theoretical Economics, 5, Article 1

Kushi LH, Doyle C, McCullough M, Rock CL, Demark-Wahnefried W, Bandera EV, Gapstur S, Patel AV, Andrews K, Gansler T (2012) American Cancer Society guidelines on nutrition and physical activity for cancer prevention: reducing the risk of cancer with healthy food choices and physical activity. CA Cancer J Clin 62:30-67

Larsson L (2006) Sick of being unemployed? Interactions between unemployment and sickness insurance. Scand J Econ 108:97-113

Lindahl M (2005) Estimating the effect of income on health and mortality using lottery prizes as exogenous source of variation in income. J Hum Res 40(1):144-168

Lleras-Muney A (2005) The relationship between education and adult mortality in the United States. Rev Econ Stud 72:189-221

Lodin, S.-O. (2009). Professorn som blev näringslivstorped: Min tid i skattepolitiken. Ekerlids Förlag

Lundborg P, Nilsson M, Vikström J (2015) Heterogeneity in the impact of health shocks on labour outcomes: evidence from Swedish workers. Oxf Econ Pap 67:715-739

Mankiw NG, Zeldes SP (1991) The consumption of stockholders and nonstockholders. J Financ Econ 29:97112

Marks NF, Jun H, Song J (2007) Death of parents and adult psychological and physical well-being: a prospective U.S. national study. J Fam Issues 28:1611-1638

Marmot M (1999) Multi-level approaches to understanding social determinants. In: Berkman L, Kawachi I (eds) Social Epidemiology. Oxford University Press, Oxford

Marmot M, Feeney A, Shipley M, North F, Syme SL (1995) Sickness absence as a measure of health status and functioning: from the UK Whitehall II study. J Epidemiol Community Health 49:124-130

McGinnis JM, Foege WH (1993) Actual causes of death in the United States. JAMA 270:2207-2212

Meer J, Miller DL, Rosen H (2003) Exploring the health-wealth nexus. J Health Econ 22:713-730

Michaud PC, van Soest A (2008) Health and wealth of elderly couples: causality tests using dynamic panel data models. J Health Econ 27:1312-1325

Mokdad AH, Marks JS, Stroup DF, Gerberding JL (2004) Actual causes of death in the United States, 2000. JAMA 291:1238-1245

Murray C, Chen L (1992) Understanding morbidity change. Popul Dev Rev 18:481-503

Muurinen J-M (1982) Demand for health: a generalized Grossman model. J Health Econ 1:5-28

Nordblom K, Ohlsson H (2006) Tax avoidance and intra-family transfers. J Public Econ 90:1669-1680

Ohlsson H (2011) The legacy of the Swedish gift and inheritance tax, 1884-2004. Eur Rev Econ Hist 15:539569

Poterba JM, Samwick AA (2003) Taxation and household portfolio composition: US evidence from the 1980s and 1990s. J Public Econ 87:5-38

Rostila M, Saarela JM (2011) Time does not heal all wounds: mortality following the death of a parent. J Marriage Fam 73:236-249

Ruhm CJ (2000) Are recessions good for your health? Q J Econ 115:617-650

Ruhm CJ (2003) Good times make you sick. J Health Econ 22:637-658

Scharlach AE (1991) Factors associated with filial grief following the death of an elderly parent. Am J Orthopsychiatry 61:307-313 
Schulz R, Mendelsohn A, Haley W, Mahoney D, Allen R, Zhang MS, Thompson L, Belle B (2003) End-oflife care and the effects of bereavement on family caregivers of persons with dementia. N Engl J Med 349: 1936-1942

Schwandt, H. (2014). Wealth shocks and health outcomes: evidence from stock market fluctuations, CEP discussion paper 1281 , July

Silfverberg, C. (2005). Slopad arvs- och gåvoskatt, Skattenytt 2005

Smith JP (1999) Healthy bodies and thick wallets: the dual relation between health and economic status. J Econ Perspect 13:145-166

Smith JP (2004) Unraveling the SES health connection. Popul Dev Rev 30:108-132

Smith JP (2005) Consequences and predictors of new health events. In: Wise D (ed) Analyses in the economics of Aging. University of Chicago Press, Chicago

Snyder SE, Evans WN (2006) The effect of income on mortality: evidence from the social security notch. Rev Econ Stat 88:482-495

SOU 2002:52. Beskattning av småföretagare, del II. Generationsskiften. Betänkande av 3:12-utredningen. Fritzes

SOU 2003:3. Egendomsskatter. Dämpningsregel för fastighetsskatten och sänkt arvsskatt. Fritzes

SOU 2004:66. Egendomsskatter. Reform av arvs- och gåvoskatter. Slutbetänkande av Egendomsskattekommittén. Fritzes

Straus J, Thomas D (2008) Health over the life course. In: Schultz TP, Strauss J (eds) Handbook of development economics volume 4. Elsevier

Umberson D, Chen MD (1994) Effects of a parent's death on adult children: relationship salience and reaction to loss. Am Sociol Rev 59:152-168

Winkelmann R., Oswald A. J., and N. Powdthavee (2010). What happens to people after winning the lottery? Paper presented at the 2011 EEA-ESEM Congress. Available at: http:/www.eea-esem. com/files/papers/EEA-ESEM/2011/132/paper.pdf

Wolff EN (2002) Inheritances and wealth inequality, 1989-1998. Am Econ Rev 92:260-264

World Health Organization (WHO) (2002). World health report 2002: reducing risks, promoting healthy life. Geneva, Switzerland.

Wu S (2003) The effects of health events on the economic status of married couples. J Hum Resour 38:219230 